\title{
Performance prediction of full-scale ship and analysis by means of on-board monitoring. Part 2: Validation of full-scale performance predictions in actual seas
}

\author{
Hideo Orihara' ${ }^{1} \cdot$ Masaru Tsujimoto $^{2}$
}

Received: 9 July 2017 / Accepted: 22 November 2017 / Published online: 18 December 2017

(c) The Author(s) 2017. This article is an open access publication

\begin{abstract}
In this paper, full-scale ship performance in actual seas, which was predicted by the method described in part 1 of the present study, was validated through a comparison with onboard monitored data. The full-scale performance of a large bulk carrier was monitored by a dedicated on-board monitoring system, and the monitored data were thoroughly analyzed and reduced to the form of performance parameters applicable to the comparison with the prediction results. The full-scale ship performance predictions evaluated in the form of shaft power increase agreed quite well with the analyzed monitored data obtained under actual operating conditions. Thus, the effectiveness of the performance prediction method presented in this study was fully confirmed.
\end{abstract}

Keywords Full-scale ship · Onboard monitoring · Performance in a seaway · Validation of performance predictions

\section{Introduction}

In order to reduce greenhouse gas emissions from ships, fuel saving by improving the hull form and the power plant systems has been strongly demanded. For this reason, confirmation of whether the ship performance is achieved as designed and reflection in new ship design have become more important.

Part 1 of this study described a method for predicting ship performance in actual seas. In this paper (part 2 of the present study), the effectiveness of the prediction method is evaluated through a comparison of full-scale performance monitoring and analysis results with the performance predictions obtained from the method described in the part 1.

For full-scale performance monitoring and analysis, we employed the "Sea-Navi" voyage support system [1,2]. This system continuously monitors items including the ship's

Hideo Orihara

orihara-hideo@jmuc.co.jp

1 Technical Research Center, Japan Marine United Corporation, Tsu, Mie, Japan

2 Performance of Ships in Actual Seas Research Group, Fluids Engineering and Hull Design Department, National Maritime Research Institute, National Institute of Maritime, Port and Aviation Technology, Tokyo, Japan position, speed, power and fuel consumption, and weather conditions. The monitored performance data are statistically analyzed by an on-board subsystem in an automatic manner for a specified duration of time to reduce the data size and cost of analysis work. The statistically analyzed data are then sent to a shore-side subsystem and examined by a rigorous analysis method, as will be described in the present study.

It has frequently been stated that full-scale on-board performance data are so unreliable and inconsistent that, considering the large amount of work involved in eliminating the effects of many disturbing factors, the detailed analysis of such data is not worthwhile compared to the analysis of new-building speed trial data, but this has not been the author's experience. It is true that the performance data recorded on board are subject to the effects of a variety of disturbances and are difficult to apply to detailed analysis on a hydrodynamic basis. However, when a sufficient amount of data is available and an appropriate analysis method such as that presented in this paper is employed, it is possible to obtain a high-quality performance evaluation with accuracy comparable to the results of normal new-building speed trials. In any case, it is apparent that the final criterion of ship performance must obviously be the results that are consistently monitored and analyzed in service, and the ship designer should finally accept this position. 
Service performance monitoring and analysis has a long history and has been utilized for the management of ship operations over the years. A number of works have been done on service performance analysis by utilizing abstract log data (e.g. [3-5]). In recent years, many on-board performance monitoring studies which were conducted in a similar way to that employed in the present study have been reported (e.g. [6-11]).

In normal full-scale ship performance predictions in the design stage, the ship's performance is evaluated under strictly defined weather conditions. In the normal practice in ship design, the still-water condition, which means no wind and no waves, is the principal weather condition for the performance evaluation. In addition to this condition, other specifically defined weather conditions such as Beaufort wind force scale-based conditions have been employed for performance in a seaway. Thus, the primary consideration in this paper is placed on the evaluation of full-scale performance under these specifically defined weather conditions and the validation of the performance predictions.

A brief description of the on-board monitoring system employed in the present study is given in the next section. Next, a physics-based full-scale performance analysis method is described in detail. Finally, the effectiveness of the present full-scale performance prediction method described in part 1 is thoroughly validated by comparing the results of predictions with the analyzed results obtained on a large bulk carrier in the fully loaded condition in actual seas.

\section{On-board performance monitoring system}

The on-board monitoring system "Sea-Navi" voyage support system [1] is employed in this study. The typical configuration of the "Sea-Navi" monitoring system is shown in Fig. 1. This system primarily consists of a suite of sensors (whose combination differs for a particular ship) and the system PC, which is used to acquire, analyze, and display data. Most hull-related data (ship's speed, course, heading wind, rudder angle, etc.) are obtained from the Voyage Data Recorder (VDR) as LAN output data. Machinery-related data (fuel-oil flow rate, fuel-oil temperature, shaft power, etc.) are obtained from the engine-room data logger. Ship motions and encountered waves are optional monitoring items and are measured by using dedicated motion sensors and a radar wave analyzer. Other on-board monitoring systems similar to "Sea-Navi" in system configuration have been employed in many service performance studies (e.g. [12-14]).
Fig. 1 Configuration of "SeaNavi" on-board monitoring system

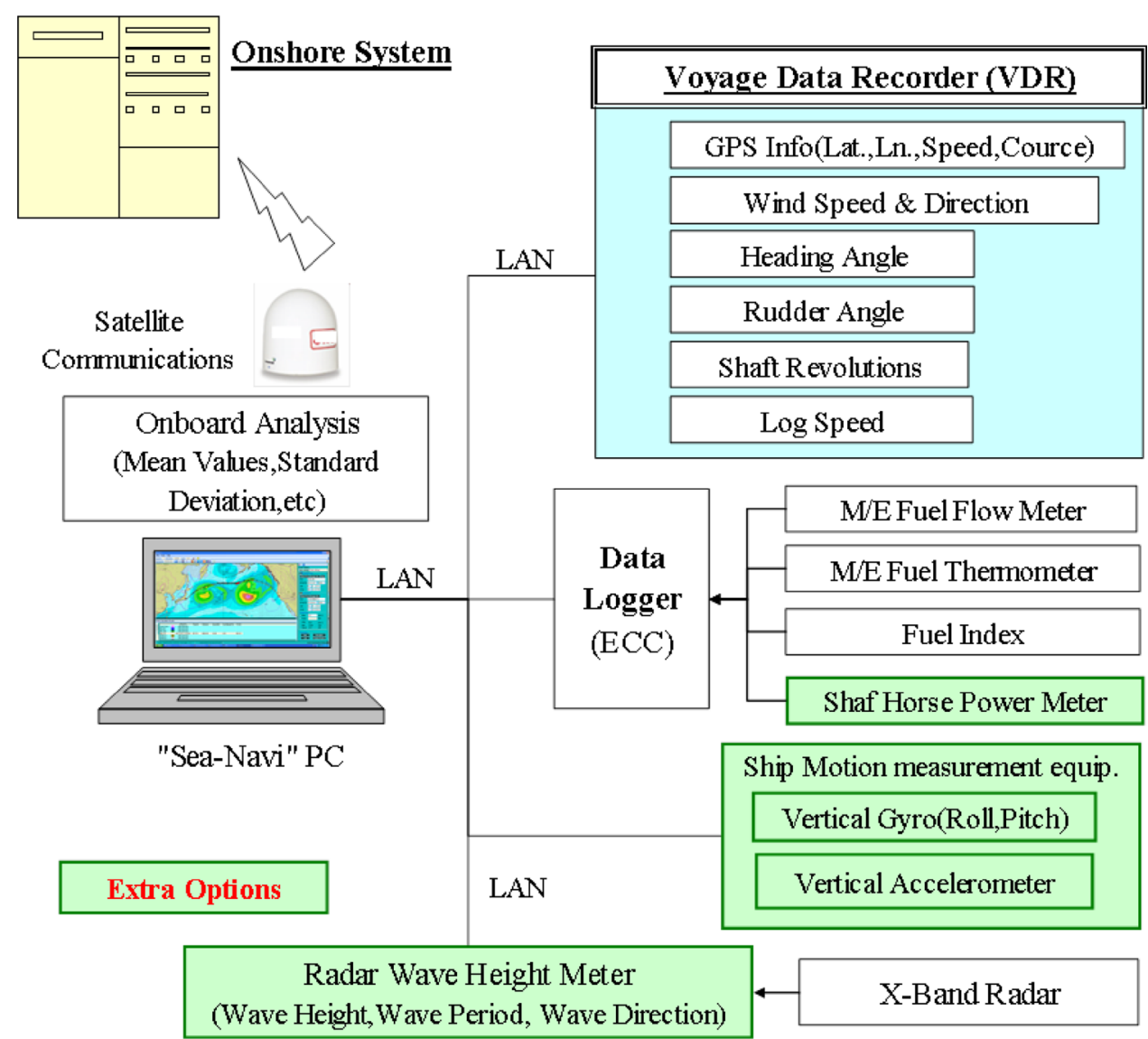


The measured data are merged as a time-series data file of 20 min length containing all the data items. Then, a statistical analysis of the time-series data is conducted in the system PC. The average, minimum, maximum, standard deviation, significant value, and zero up-cross period are calculated for all the data items at intervals of $20 \mathrm{~min}$.

\section{Full-scale performance analysis method}

The monitored performance data are analyzed so as to give results as the propulsive power increase due to encountered weather effects on the basis of the Beaufort wind force (BF) scale. The analysis of monitored data is divided into the following four steps:

1. Step 1: Scrutiny of monitored data.

2. Step 2: Estimation of resistance increases due to encountered disturbances.

3. Step 3: Correction of ship's performance for the effect of disturbances.

4. Step 4: Evaluation of ship's performance in standard weather conditions.

\subsection{Scrutiny of monitored data}

In order to remove uncertainty of the data and conduct the analysis under an equivalent basis to the greatest extent possible, a certain group of monitored data is selected for the analysis.

For the performance analysis in the still-water condition (i.e. no wind and no wave condition), the following criteria are specified in the data scrutiny:

1. The true wind speed is less than a certain threshold value to eliminate data under strong winds.

2. The significant wave height is less than a certain threshold value to eliminate data in large waves.

3. The average and standard deviation of the rudder angle during a certain duration of time are within certain threshold values to eliminate the data during intentional steering operations.

4. Maximum difference of the rudder angle during a certain duration of time are within certain threshold values to eliminate the data during intentional steering operations.

5. Propeller revolutions are greater than those corresponding to the minimum output of the main engine capable of continuous running to eliminate the data during excessively slow speeds, for example, during harbor maneuvers.

6. The difference in propeller revolutions during a certain duration of time is within a certain threshold value of the maximum propeller revolution corresponding to $\mathrm{MCO}$ to eliminate the data during accelerating or decelerating operations.

7. The pitch angle is less than certain threshold values to eliminate data in rough weather conditions.

8. The roll angle is less than certain threshold values to eliminate data in rough weather conditions.

For the performance analysis in standard wind and wave conditions (i.e. under the effect of specific wind and wave magnitudes), the following criteria are specified in the data scrutiny:

1. Difference between average true wind angle and mean wave direction is less than a certain threshold value to eliminate data under strong swells.

2. Difference between wind-speed based Beaufort scale and wave-height based Beaufort scale is less than a certain threshold value to eliminate data in strong swells or gusty winds.

3. Standard deviation of true wind direction during certain duration of time is within certain threshold values to eliminate the data under changing wind conditions.

4. Standard deviation of the rudder angle during certain duration of time is within certain threshold values to eliminate the data during intentional steering operations.

5. Maximum difference of the rudder angle during certain duration of time is within certain threshold values to eliminate the data during intentional steering operations.

6. Standard deviation of the heading angle during certain duration of time is within certain threshold values to eliminate the data during intentional steering operations.

7. Propeller revolutions are greater than those corresponding to the minimum output of the main engine capable of continuous running to eliminate the data during excessively slow speeds, for example, during harbor maneuvers.

8. The difference in propeller revolutions during certain duration of time is within a certain threshold value of the maximum propeller revolution corresponding to MCO to eliminate the data during accelerating or decelerating operations.

\subsection{Estimation of resistance increases due to encountered disturbances}

The increases in ship's resistance due to environmental and external disturbances such as wind, waves, steering and drifting are estimated. The directions of wind and waves relative to the ship's heading and ship's drifting angle are defined as shown in Fig. 2.

The resistance increase due to wind $\left(\Delta R_{\text {wind }}\right)$ is calculated by

$\Delta R_{\text {wind }}=\frac{1}{2} \rho_{\mathrm{a}} \cdot A_{\mathrm{T}} \cdot\left\{C_{\mathrm{AA}}\left(\Psi_{\text {wind }, \mathrm{R}}\right) \cdot V_{\text {wind } \mathrm{R}}^{2}-C_{\mathrm{AA}}(0) \cdot V_{\mathrm{G}}^{2}\right\}$, 


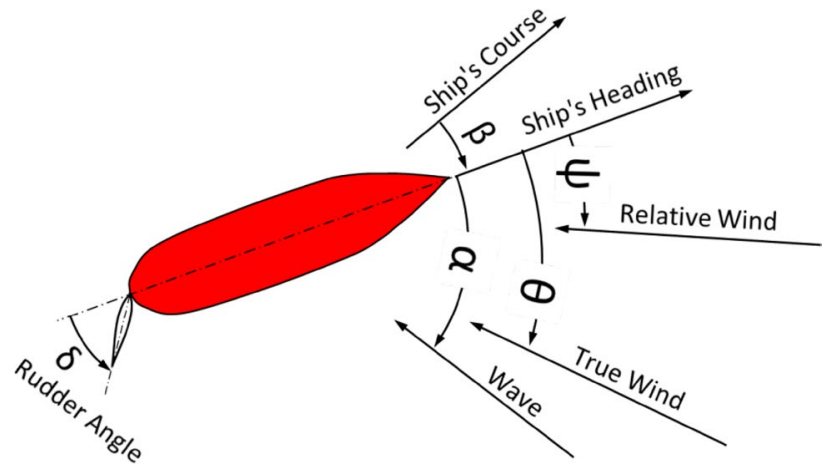

Fig. 2 Definition of ship's course and heading and wind and wave directions

where $\rho_{\mathrm{a}}$ is the mass density of air, $A_{\mathrm{T}}$ is the transverse projected area above the waterline including the superstructure, and $C_{\mathrm{AA}}()$ is the wind resistance coefficient; $C_{\mathrm{AA}}(0)$ is the wind coefficient in a head wind, $\Psi_{\text {wind,R }}$ is the relative wind direction, $V_{\text {wind,R }}$ is the relative wind speed, and $V_{\mathrm{G}}$ is the ship's speed over ground. Since the relative wind resistance due to self-running of a ship is included in the still-water resistance of a ship in the present method, the resistance increase due to wind is evaluated by excluding the relative wind resistance due to self-running from the total wind resistance as shown in the right-hand side of Eq. (1)

The wind resistance coefficient is based on the data derived from model tests in a wind tunnel or from data calculated by the method in [15].

The added resistance in waves which is the resistance increase due to wave effects $\left(\Delta R_{\text {wave }}\right)$ is presented as a summation of the resistance increases due to wind waves and swells, and is calculated by

$$
\begin{aligned}
\Delta R_{\mathrm{wave}}= & \rho_{\mathrm{w}} \cdot g \cdot\left(\frac{B^{2}}{L}\right) \cdot\left\{H^{2} \cdot C_{\mathrm{AW}, \mathrm{WD}}\left(\alpha_{\mathrm{WDWV}}, T_{\mathrm{m}, \mathrm{WDWV}}\right)\right. \\
& \left.+H_{\mathrm{SWLL}}^{2} \cdot C_{\mathrm{AW}, \mathrm{SL}}\left(\alpha_{\mathrm{SWLL}}, T_{\mathrm{m}, \mathrm{SWLL}}\right)\right\}
\end{aligned}
$$

where $\rho_{\mathrm{w}}$ is the mass density of water, $g$ is the acceleration of gravity, $B$ is the ship's breadth, $L$ is the ship's length, $H$ is the significant height of wind waves, $H_{\mathrm{SWLL}}$ is the height of swell, $C_{\mathrm{AW}, \mathrm{WD}}()$ is the coefficient for the added resistance due to wind waves, $C_{\mathrm{AW}, \mathrm{SL}}()$ is the coefficient for the added resistance due to swell, and $\alpha_{\mathrm{WDWV}}$ is the encounter angle of wind waves; 0 means head waves, $\alpha_{\text {SwLL }}$ is the encounter angle of swell; 0 means head swell, $T_{\mathrm{m} \text {,WDwv }}$ is the mean period of wind waves, and $T_{\mathrm{SWLL}}$ is the period of swell.

$C_{\mathrm{AW}, \mathrm{WD}}()$, and $C_{\mathrm{AW}, \mathrm{SL}}()$ are calculated by linear superposition of the directional wave spectrum and the response function of the mean resistance increase in regular waves. The response function of the mean wave resistance increase in regular waves is based on the data derived from tests in a ship model basin or from data calculated by the method in [15].

Resistance increase due to steering $\left(\Delta R_{\text {rud }}\right)$ is calculated by

$\Delta R_{\mathrm{rud}}=\left(1-t_{\mathrm{R}}\right) \cdot F_{\mathrm{N}} \cdot \sin \delta$,

where $t_{\mathrm{R}}$ is the deduction factor for resistance due to steering, $F_{\mathrm{N}}$ is the normal force acting on the rudder, and $\delta$ is the rudder angle. by

Resistance increase due to drifting $\left(\Delta R_{\mathrm{drft}}\right)$ is calculated

$\Delta R_{\mathrm{drft}}=\frac{1}{2} \cdot \rho \cdot V^{2} \cdot L \cdot d \cdot C_{\mathrm{DRFT}, X}(\beta)$,

where $V$ is the ship's speed through water, $\mathrm{d}$ is the ship's mean draft, $C_{\mathrm{DRFT}, X}()$ is the coefficient for the resistance increase due to drifting of the ship, and $\beta$ is the drifting angle of the ship.

$t_{\mathrm{R}}$ and $C_{\mathrm{DRFT}, X}()$ are based on the data derived from tests in a ship model basin. In cases where a database covering ships of similar type is available, those data can be used instead of carrying out model tests.

Resistance increase due to yaw $\left(\Delta R_{\text {yaw }}\right)$ is calculated by

$$
\begin{aligned}
\Delta R_{\text {yaw }} & =0.4 \cdot L \cdot\left(M+C_{\mathrm{B}} \cdot m_{y}\right) \cdot \bar{r}^{2} \\
& =0.2 \cdot \rho \cdot L \cdot \nabla \cdot\left(1+C_{\mathrm{B}} \cdot m_{y}^{\prime}\right) \cdot \omega_{\Psi}^{2} \cdot \Psi_{\mathrm{a}}^{2},
\end{aligned}
$$

where $M(=\rho \nabla)$ is the ship's mass, $m_{y}$ is added mass in the lateral direction of the ship, $\vec{r}^{2}\left(=0.5\left(2 \pi \Psi_{\mathrm{a}} / T_{\Psi}\right)^{2}\right)$ is the square of average of the yaw rate, $\nabla$ is the ship's displaced volume, $C_{\mathrm{B}}$ is the ship's block coefficient $(=\nabla /(L \cdot B \cdot d)), m_{y}{ }^{\prime}$ $\left(=m_{y} /(\rho \cdot L \cdot B \cdot d)\right)$ is the normalized $m_{y}, \omega_{\Psi}\left(=2 \pi / T_{\Psi}\right)$ is the circular frequency of yaw motion, $\Psi_{\mathrm{a}}$ is the amplitude of yaw motion, and $T_{\Psi}$ is the period of yaw motion.

\subsection{Correction of ship's performance for effect of disturbances}

After scrutiny of the monitored data, the speed-power performance of the ship is corrected for the effect of external disturbances to obtain the performance in the specified weather and operating conditions. The procedure for the performance correction is established based on the resistance and the resistance and thrust identity method $[16,17]$. The resistance and thrust identity method is principally based on the assumptions that, over the normal range of full-scale ship operations, the ship's propeller produces the same thrust in a wake field of wake fraction $w$ as in open water with speed $V_{\mathrm{w}}(1-w)$ and that the ship's total resistance in a seaway is represented by the linear summation of the stillwater resistance and resistance increases due to disturbances encountered. 
The ship's speed-power performance correction calculation is made by using the ship's resistance/self-propulsive characteristic and propeller open-water characteristic data obtained from tests in a ship model basin or by a theoretical method which has accuracy equivalent to model tests. For ease of correction, propeller open water characteristics are described by the following formulae:

$K_{\mathrm{T}}(J)=a_{\mathrm{T}} J^{2}+b_{\mathrm{T}} J+c_{\mathrm{T}}$

$K_{\mathrm{Q}}(J)=a_{\mathrm{Q}} J^{2}+b_{\mathrm{Q}} J+c_{\mathrm{Q}}$

$\tau_{\mathrm{P}}(J)=a_{\mathrm{T}}+b_{\mathrm{T}} / J+c_{\mathrm{T}} / J^{2}$,

where $K_{\mathrm{T}}()$ is the thrust coefficient, $K_{\mathrm{Q}}()$ is the torque coefficient, $\tau_{\mathrm{P}}()$ is the load factor $\left(=K_{\mathrm{T}}(J) / J^{2}\right), J$ is the propeller advance coefficient $\left(=V_{\mathrm{A}} / n_{\mathrm{P}} D_{\mathrm{P}}\right), V_{\mathrm{A}}$ is the speed of flow into the propeller, $n_{\mathrm{P}}$ is the propeller shaft speed, $D_{\mathrm{P}}$ is the propeller diameter, $a_{\mathrm{T}}, b_{\mathrm{T}}, c_{\mathrm{T}}$, are the factors for the thrust coefficient curve, and $a_{\mathrm{Q}}, b_{\mathrm{Q}}, c_{\mathrm{Q}}$, are the factors for the torque coefficient curve.

The correction is based on the resistance increases corresponding to the external disturbances estimated by Eq. (1) through (5). The ship's total resistance is calculated from the monitored ship's delivered power. The total resistance is then corrected by deducing the estimated resistance increases, and finally, the corrected speed-power performance is obtained.

The performance correction is conducted for the following two standard weather conditions:

1. Still-water condition (no wind and no wave condition) for the verification of the ship's normally contracted performance.

2. Beaufort weather condition (wind and wave conditions specified according to the Beaufort wind force scale [18]) for the verification of the ship's performance in a seaway (see Table 1).

The adaptation of the wind speed-based BF scale as a weather scale for the analysis is based on the consideration that the evaluation of prevailing wind conditions is far more accurate than the corresponding assessment of the wave conditions.

\subsubsection{Performance correction to the still-water condition}

The following describes the procedure for the correction of the ship's performance to the still-water condition:

First, the delivered power to the propeller $\left(P_{\mathrm{D}, \mathrm{S}}\right)$ is calculated from the measured shaft power $\left(P_{\mathrm{S}, \mathrm{S}}\right)$ by

$P_{\mathrm{D}, \mathrm{S}}=P_{\mathrm{S}, \mathrm{S}} \cdot \eta_{\mathrm{S}}$,

where $P_{\mathrm{S}, \mathrm{S}}$ is the measured shaft power, and $\eta_{\mathrm{S}}$ is the shaft efficiency.
Table 1 Beaufort scale-based standard weather condition

\begin{tabular}{llll}
\hline $\begin{array}{l}\text { Beaufort } \\
\text { scale }\end{array}$ & Wind speed (m/s) & $\begin{array}{l}\text { Sig. wave } \\
\text { height }(\mathrm{m})\end{array}$ & $\begin{array}{l}\text { Mean wave } \\
\text { period }^{\mathrm{a}}(\mathrm{s})\end{array}$ \\
\hline 1 & 0.90 & 0.1 & 1.2 \\
2 & 2.45 & 0.2 & 1.7 \\
3 & 4.40 & 0.6 & 3.0 \\
4 & 6.70 & 1.0 & 3.9 \\
5 & 9.35 & 2.0 & 5.5 \\
6 & 12.30 & 3.0 & 6.7 \\
7 & 15.50 & 4.0 & 7.7 \\
8 & 18.95 & 5.5 & 9.1 \\
\hline
\end{tabular}

${ }^{\text {a }}$ Wave period $\left(T_{\mathrm{m}}\right)$ is calculated from wave height as $T_{\mathrm{m}}=3.86 \sqrt{H_{\mathrm{W}}}$

The propeller torque coefficient in the monitored condition $\left(K_{\mathrm{Q}, \mathrm{S}}\right)$ is calculated by

$K_{\mathrm{Q}, \mathrm{S}}=\frac{P_{\mathrm{D}, \mathrm{S}} \cdot \eta_{\mathrm{R}}}{2 \pi \cdot \rho_{\mathrm{w}} \cdot n_{\mathrm{s}}^{3} \cdot D_{\mathrm{P}}^{5}}$,

where $\eta_{\mathrm{R}}$ is the relative rotative efficiency of the propeller, $n_{\mathrm{S}}$ is the measured shaft speed, and $D_{\mathrm{P}}$ is the propeller diameter.

The propeller advance coefficient in the monitored condition $\left(J_{\mathrm{S}}\right)$ is determined by Eq. (11) by using the torque coefficient $K_{\mathrm{Q}, \mathrm{S}}$,

$J_{\mathrm{S}}=\frac{-b_{\mathrm{Q}}-\sqrt{b_{\mathrm{Q}}^{2}-4 a_{\mathrm{Q}} \cdot\left(c_{\mathrm{Q}}-K_{\mathrm{Q}, \mathrm{S}}\right)}}{2 a_{\mathrm{Q}}}$.

The thrust coefficient in the monitored condition $K_{\mathrm{T}, \mathrm{S}}$ is obtained by Eq. (6) by using the propeller advance coefficient $J_{\mathrm{S}}$. Then, the propeller efficiency $\left(\eta_{\mathrm{O}, \mathrm{S}}\right)$ is obtained as

$\eta_{\mathrm{O}, \mathrm{S}}=\frac{J_{\mathrm{S}}}{2 \pi} \cdot \frac{K_{\mathrm{T}, \mathrm{S}}}{K_{\mathrm{Q}, \mathrm{S}}}$.

The load factor of the propeller $\tau_{\mathrm{S}}$ is calculated as

$\tau_{\mathrm{S}}=\frac{K_{\mathrm{T}, \mathrm{S}}}{J_{\mathrm{S}}^{2}}$

The full-scale propeller wake fraction is calculated by

$1-w_{\mathrm{S}}=\frac{V_{\mathrm{a}}}{V_{\mathrm{w}}}=\frac{J_{\mathrm{S}} \cdot n_{\mathrm{S}} \cdot D_{\mathrm{p}}}{V_{\mathrm{w}}}$,

where $V_{\mathrm{w}}$ is the ship's speed through water.

The total resistance in the measured condition $R_{\mathrm{T}, \mathrm{S}}$ is also estimated by using the propeller load factor $\tau_{\mathrm{S}}$ as

$R_{\mathrm{T}, \mathrm{S}}=\rho_{\mathrm{w}} \cdot V_{\mathrm{w}}^{2} \cdot D_{\mathrm{P}}^{2} \cdot(1-t) \cdot\left(1-w_{\mathrm{S}}\right)^{2} \cdot \tau_{\mathrm{S}}$,

where $t$ is the thrust deduction factor. 
The propulsive efficiency coefficient $\eta_{\mathrm{D}, \mathrm{S}}$ is calculated by using the propeller efficiency and self-propulsion factors as

$\eta_{\mathrm{D}, \mathrm{S}}=\eta_{\mathrm{O}, \mathrm{S}} \cdot \eta_{\mathrm{R}} \cdot \frac{1-t}{1-w_{\mathrm{S}}}$.

The total resistance is corrected by subtracting the estimated resistance increases from $R_{\mathrm{T}, \mathrm{S}}$ as

$R_{\mathrm{T}, \mathrm{S}, \mathrm{Crct}}=R_{\mathrm{T}, \mathrm{S}}-\left(\Delta R_{\text {wind }}+\Delta R_{\mathrm{wave}}+\Delta R_{\mathrm{rud}}+\Delta R_{\mathrm{drft}}+\Delta R_{\text {yaw }}\right)$.

The corrected load factor of the propeller is determined by using the corrected total resistance as

$\tau_{\mathrm{S}, \text { Cret }}=\frac{R_{\mathrm{T}, \mathrm{S}, \text { Crct }}}{\rho_{\mathrm{w}} \cdot V_{\mathrm{w}}^{2} \cdot D_{\mathrm{P}}^{2} \cdot(1-t) \cdot\left(1-w_{\mathrm{S}}\right)^{2}}$.

The corrected propeller advance coefficient is determined by Eq. (18) by using the corrected load factor $\tau_{\mathrm{S} \text {,Crct }}$

$J_{\mathrm{S}, \mathrm{Crct}}=\frac{-b_{\mathrm{T}}-\sqrt{b_{\mathrm{T}}^{2}-4 c_{\mathrm{T}} \cdot\left(a_{\mathrm{T}}-\tau_{\mathrm{S}, \mathrm{Crct}}\right)}}{2\left(a_{\mathrm{T}}-\tau_{\mathrm{S}, \mathrm{Crct}}\right)}$.

The thrust and torque coefficients of the propeller are corrected by substituting $J_{S, \text { Crct }}$ in Eqs. (6) and (7). Then, the corrected propeller efficiency is obtained as

$\eta_{\mathrm{O}, \mathrm{S}, \mathrm{Crct}}=\frac{J_{\mathrm{S}, \mathrm{Crct}}}{2 \pi} \cdot \frac{K_{\mathrm{T}, \mathrm{S}, \mathrm{Crct}}}{K_{\mathrm{Q}, \mathrm{S}, \mathrm{Crct}}}$.

The corrected propulsive efficiency coefficient is obtained as

$\eta_{\mathrm{D}, \mathrm{S}, \mathrm{Crct}}=\eta_{\mathrm{O}, \mathrm{S}, \mathrm{Crct}} \cdot \eta_{\mathrm{R}} \cdot \frac{1-t}{1-w_{\mathrm{S}}}$.

Then, the required correction for delivered power $\Delta P$ is calculated as

$\Delta P_{\mathrm{D}, \mathrm{S}}=\frac{\left(R_{\mathrm{T}, \mathrm{S}}-R_{\mathrm{T}, \mathrm{S}, \mathrm{Crct}}\right) \cdot V_{\mathrm{w}}}{\eta_{\mathrm{D}, \mathrm{S}, \mathrm{Crct}}}-P_{\mathrm{D}, \mathrm{S}}\left(1-\frac{\eta_{\mathrm{D}, \mathrm{S}}}{\eta_{\mathrm{D}, \mathrm{S}, \mathrm{Crct}}}\right)$.

The corrected delivered power to the propeller is obtained as follows:

$P_{\mathrm{D}, \mathrm{S}, \mathrm{Crct}}=P_{\mathrm{D}, \mathrm{S}}-\Delta P_{\mathrm{D}, \mathrm{S}}$.

The corrected shaft power is obtained as

$P_{\mathrm{S}, \mathrm{S}, \text { Cret }}=P_{\mathrm{D}, \mathrm{S}, \mathrm{Crct}} / \eta_{\mathrm{S}}$

The corrected propeller speed is obtained from the corrected propeller advance coefficient as

$n_{\mathrm{S}, \text { Crct }}=\frac{\left(1-w_{\mathrm{S}}\right) \cdot V_{\mathrm{w}}}{J_{\mathrm{S}, \text { Crct }} \cdot D_{\mathrm{P}}}$.

\subsubsection{Performance correction to the Beaufort standard weather condition}

The procedure for correction of the ship's performance to the Beaufort standard weather condition is the same as for the still-water condition except for the total resistance correction (Eq. (17)). In the case of Beaufort standard weather, the total resistance is corrected only for the difference of the wave effect between the actual weather condition and the measured wind speed-based the Beaufort weather condition. In the Beaufort standard weather condition, the wave condition is specified as follows (see Fig. 3):

1. Wave height $\left(H_{\mathrm{BF}-\text { wind }}\right)$ : Calculated from the measured true wind speed according to Table 1 .

2. Wave period $\left(T_{\mathrm{m}, \mathrm{Wv}, \mathrm{BF}}\right)$ : Calculated from the measured true wind speed according to Table 1.

3. Wave direction $\left(\alpha_{\mathrm{WV}, \mathrm{BF}}\right)$ : Set to be the same as the measured true wind direction.

4. Characteristics: Consist of wind wave components only, with no swell component.

Here, the measured true wind speed is corrected to the value at $10 \mathrm{~m}$ above sea level by the 1/7th law of wind speed distributions by taking into account differences in the height of the anemometer.

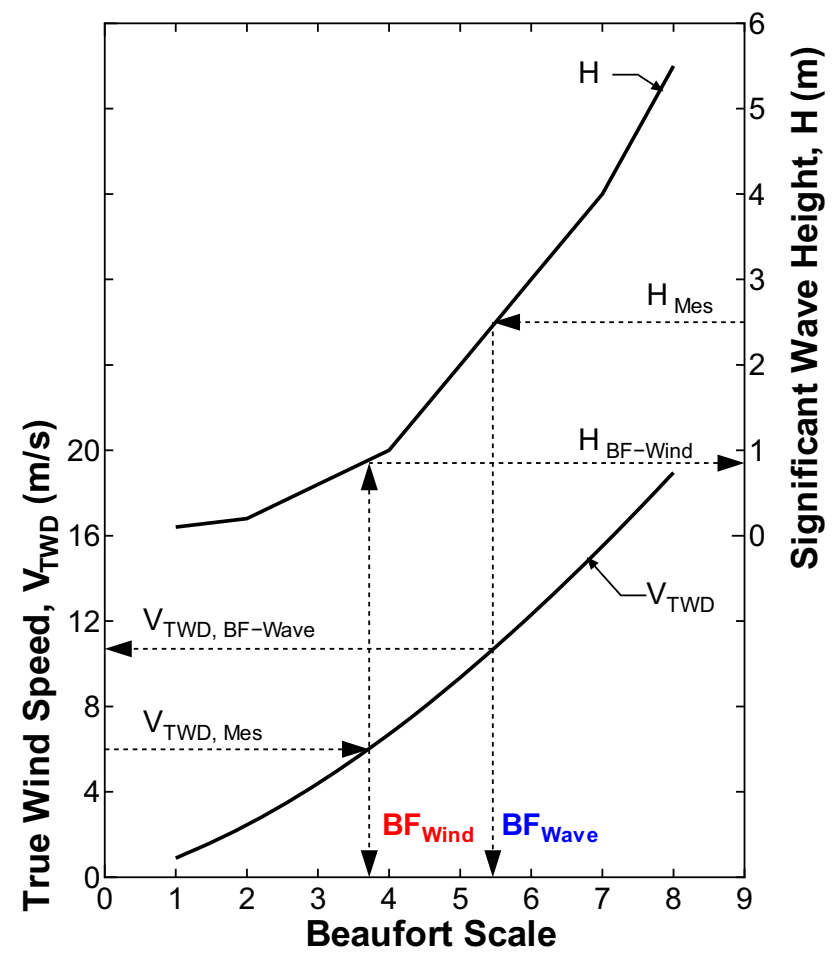

Fig. 3 Definition of Beaufort scale-based wind and wave conditions 
Thus, the total resistance is corrected by subtracting the estimated resistance increases due to effects of wind and waves and substituting the estimated resistance increase corresponding to the Beaufort standard weather condition $\left(\Delta R_{\text {wind, } \mathrm{BF}}, \Delta R_{\text {wave }, \mathrm{BF}}\right)$ :

$R_{\mathrm{T}, \mathrm{S}, \mathrm{Crct}}=R_{\mathrm{T}, \mathrm{S}}-\left(\Delta R_{\text {wind }}-\Delta R_{\text {wind, } \mathrm{BF}}\right)-\left(\Delta R_{\text {wave }}-\Delta R_{\text {wave }, \mathrm{BF}}\right)$

$\Delta R_{\text {wind, } \mathrm{BF}}$ is calculated as a resistance increase due to wind of the encountered true wind speed and the Beaufort scalebased reference wind direction $\left(\theta_{\mathrm{BF}, \mathrm{ref}}\right)$ as

$\Delta R_{\text {wind, } \mathrm{BF}}=\frac{1}{2} \rho_{\mathrm{a}} \cdot A_{\mathrm{T}} \cdot\left\{C_{\mathrm{AA}}\left(\Psi_{\text {wind, } \mathrm{BF}, \mathrm{ref}}\right) \cdot V_{\text {wind } \mathrm{R}}^{2}-C_{\mathrm{AA}}(0) \cdot V_{\mathrm{G}}^{2}\right\}$,

where $\Psi_{\text {wind,BF,ref }}$ is the relative wind direction due to the true wind direction $\theta_{\mathrm{BF}, \text { ref }}$ and the ship's speed $V_{\mathrm{G}}$. $\theta_{\mathrm{BF} \text {,ref }}$ is set based on the encountered true wind direction $(\theta)$ as follows:

$$
\begin{aligned}
\theta_{\mathrm{BF}, \text { ref }} & =0^{\circ} \quad \text { for } 0^{\circ} \leqq \theta<15^{\circ}, \\
& =30^{\circ} \quad \text { for } 15^{\circ} \leqq \theta<45^{\circ}, \\
& =60^{\circ} \quad \text { for } 45^{\circ} \leqq \theta<75^{\circ}, \\
& =90^{\circ} \quad \text { for } 75^{\circ} \leqq \theta<105^{\circ}, \\
& =120^{\circ} \quad \text { for } 105^{\circ} \leqq \theta<135^{\circ}, \\
& =150^{\circ} \quad \text { for } 135^{\circ} \leqq \theta<165^{\circ}, \\
& =180^{\circ} \quad \text { for } 165^{\circ} \leqq \theta \leqq 180^{\circ} .
\end{aligned}
$$

In the calculation of $\Delta R_{\text {wind,BF }}$, symmetry of the true wind direction relative to the ship's longitudinal plane is assumed. Performance characteristic parameters used in the full-scale performance analysis are evaluated by themethod listed in Table 2.

$\mathrm{d} R_{\text {wave, } \mathrm{BF}}$ is calculated as an added resistance in wind waves of the magnitude according to the Beaufort standard weather condition as

$\Delta R_{\mathrm{wave}, \mathrm{BF}}=\rho \cdot g \cdot\left(\frac{B^{2}}{L}\right) \cdot\left\{H_{\mathrm{BF}-\mathrm{wind}}{ }^{2} \cdot C_{\mathrm{AW}, \mathrm{WD}}\left(\alpha_{\mathrm{WV}, \mathrm{BF}}, T_{\mathrm{m}, \mathrm{WV}, \mathrm{BF}}\right)\right\}$.

\subsection{Evaluation of ship's performance in standard weather conditions}

The corrected ship's performance obtained from the calculations by the procedure described in the preceding section is used for the verification of the performance predictions conducted in the design stage. As mentioned earlier, in many cases a ship's full-scale performance is confirmed only in the trial condition (i.e. lightly loaded condition); thus, the actual performance in the fully loaded condition (normal design condition) is not verified for most ship types. In addition, as ship's speed trial before delivery is conducted under a relatively calm sea condition (usually less than Beaufort wind scale 5), the ship's performance under actual operating conditions, that is, its performance in actual seas under the influence of external disturbances including wind and waves, has not been verified so far.

By using the on-board performance monitoring and analysis methods described in this paper, a ship's performance in both the fully loaded condition and in actual seas can be evaluated and readily compared with those predictions. For

\begin{tabular}{|c|c|c|}
\hline Type & $\begin{array}{l}\text { Parameters used in the } \\
\text { analysis }\end{array}$ & Sources \\
\hline Resistance in still water & $R_{\mathrm{T}, \mathrm{S}}$ & On-board monitoring ${ }^{\mathrm{a}}$ \\
\hline \multirow[t]{3}{*}{ Self-propulsion factors } & $1-t, \eta_{\mathrm{R}}$ & Model test \\
\hline & $1-w$ & On-board monitoring ${ }^{\mathrm{a}}$ \\
\hline & $\eta_{\mathrm{S}}$ & Design data ${ }^{b}$ \\
\hline Propeller open-water characteristic & $K_{\mathrm{T}}(J), K_{\mathrm{Q}}(J)$ & Model test \\
\hline Wind resistance increase & $C_{\mathrm{AA}}(\Psi)$ & Model test \\
\hline Added resistance in waves & $C_{\mathrm{AW}}(\alpha, T)$ & $\begin{array}{l}\text { Model test and theoreti- } \\
\text { cal calculation }^{\mathrm{c}}\end{array}$ \\
\hline Steering resistance increase & $F_{\mathrm{N}}$ & Theoretical calculation $^{\mathrm{d}}$ \\
\hline Drifting resistance increase & $C_{\mathrm{DRFT}, X}(\beta)$ & Model test \\
\hline Yawing resistance increase & $m_{y}^{\prime}$ & Theoretical calculation $^{\mathrm{d}}$ \\
\hline
\end{tabular}
the evaluation of performance in the fully loaded condition, the corrected speed-power performance is compared with the prediction obtained from model test results in the format
Table 2 List of performance parameters employed in the fullscale performance analysis
${ }^{a}$ Obtained as a result of the analysis

${ }^{\mathrm{b}}$ Shaft efficiency $\left(\eta_{\mathrm{S}}\right)$ is estimated based on the shat-line configuration of the on-board propulsion plant

${ }^{\mathrm{c}}$ By the method described in Part I, in which the hybrid approach using both model test results and theoretical calculation results is employed

${ }^{\mathrm{d}}$ By the method described in part 1 
of speed-power curves. A detailed analysis of the corrected performance makes it possible to obtain model-ship correlation allowances, that is, the correction factors for the resistance and self-propulsive factors applied in the performance predictions. For the evaluation of performance under the influence of external disturbances, a comparison is usually made in terms of the performance deterioration relative to the still-water condition (no wind/wave) by using parameters such as shaft power increase or speed loss.

Shaft power increase in actual seas is defined as a percent increase of shaft power relative to that in the still-water condition (i.e. no wind and no waves) at the same ship's speed $\left(V_{\mathrm{S}}\right)$ as follows (see Fig. 4):

Shaft power increase $\equiv \frac{P_{\mathrm{S}, \mathrm{AS}}\left(V_{\mathrm{S}, \mathrm{AS}}\right)-P_{\mathrm{S}, 0}\left(V_{\mathrm{S}, \mathrm{AS}}\right)}{P_{\mathrm{S}, 0}\left(V_{\mathrm{S}, \mathrm{AS}}\right)} \times 100(\%)$,

where $P_{\mathrm{S}, \mathrm{AS}}()$ is the shaft power in actual seas, and $P_{\mathrm{S}, 0}()$ is the shaft power in still water.

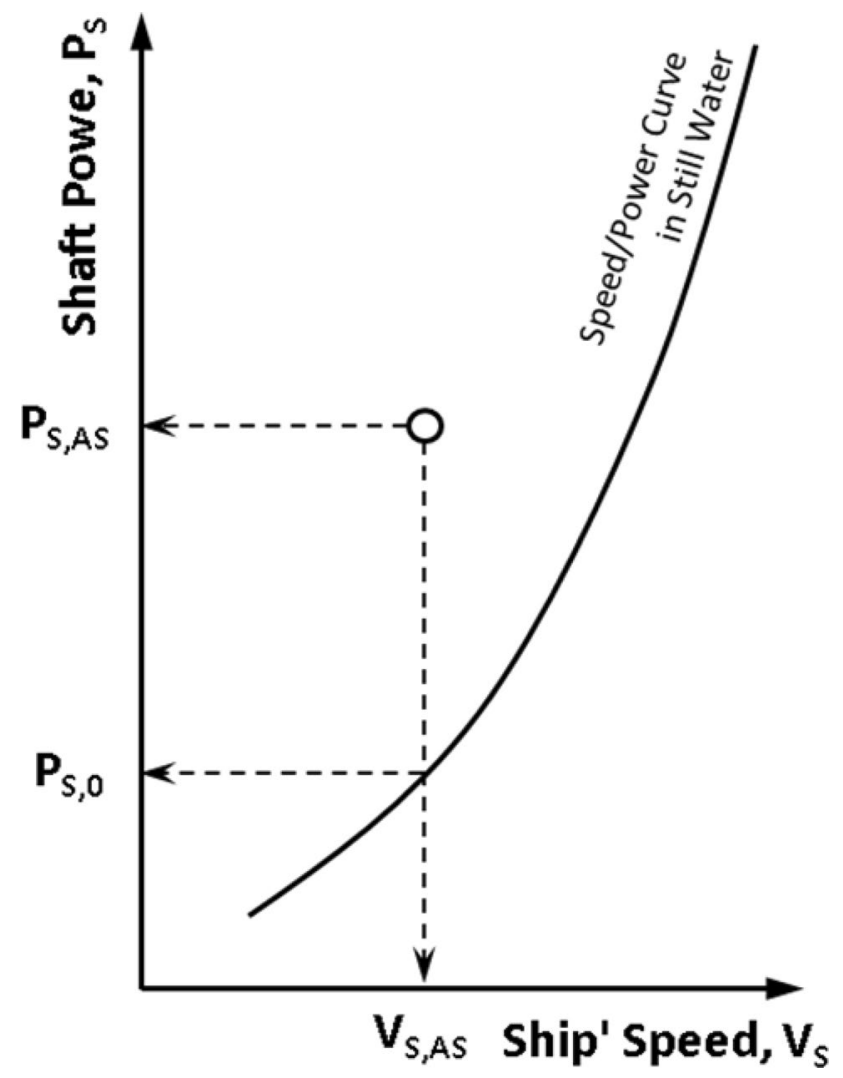

Fig. 4 Definition of shaft power increase

\section{Evaluations of ship performance predictions by comparison with full-scale monitoring data}

To evaluate the accuracy of the accuracy of ship performance prediction in actual seas, full-scale performance data of a large bulk carrier is compared with the predictions according to the prediction method described in part 1 of this study. The full-scale data are monitored by the system described in the Sect. 2 and are analyzed according to the performance analysis method described in the Sect. 3. Then the analyzed data are compared with the predictions according to the method described in part 1 . Regarding performance predictions in this section, stillwater performance is predicted using model test results, and speed-power relationship is established by a kind of Resistance and Thrust Identity Method (RTIM) since it is considered to be the most rational among the available prediction method as described in part 1.

\subsection{Subject ship}

A large bulk carrier recently built in Japan (hereinafter designated "Ship A") was selected as the subject ship for the full-scale performance monitoring and analysis. Its dimensions are approximately $320 \mathrm{~m}$ in length, $55 \mathrm{~m}$ in width, and $30 \mathrm{~m}$ in depth. Ship A has been mainly operated on the route between Brazil and East Asia.

\subsection{Results and discussion}

\subsubsection{Characteristics of monitored full-scale data}

Two voyage cases, both in the fully loaded condition, were selected for the evaluation.

The time series of the monitored data is shown in Figs. 5 and 6, which includes the encountered weather (wind speed, wave height), rudder angle (average, standard deviation (SD)), drift angle, heading angle, ship motions (pitch and roll angles), speed through water (denoted "T.W." hereafter), shaft power and shaft revolution. Since the figure of the last three items (speed through water, shaft power and shaft revolution) are confidential affairs of the ship owner and its figures cannot be disclosed due to the restriction of commercial contracts, these figures are shown here with only a relative unit scale of a magnitude of each item. All the data shown in Figs. 5 and 6 were processed over a time duration of $20 \mathrm{~min}$ from the raw time series data sampled at $1 \mathrm{~Hz}$. Except for the SD of the rudder angle, heading angle and the pitch and roll angles, 

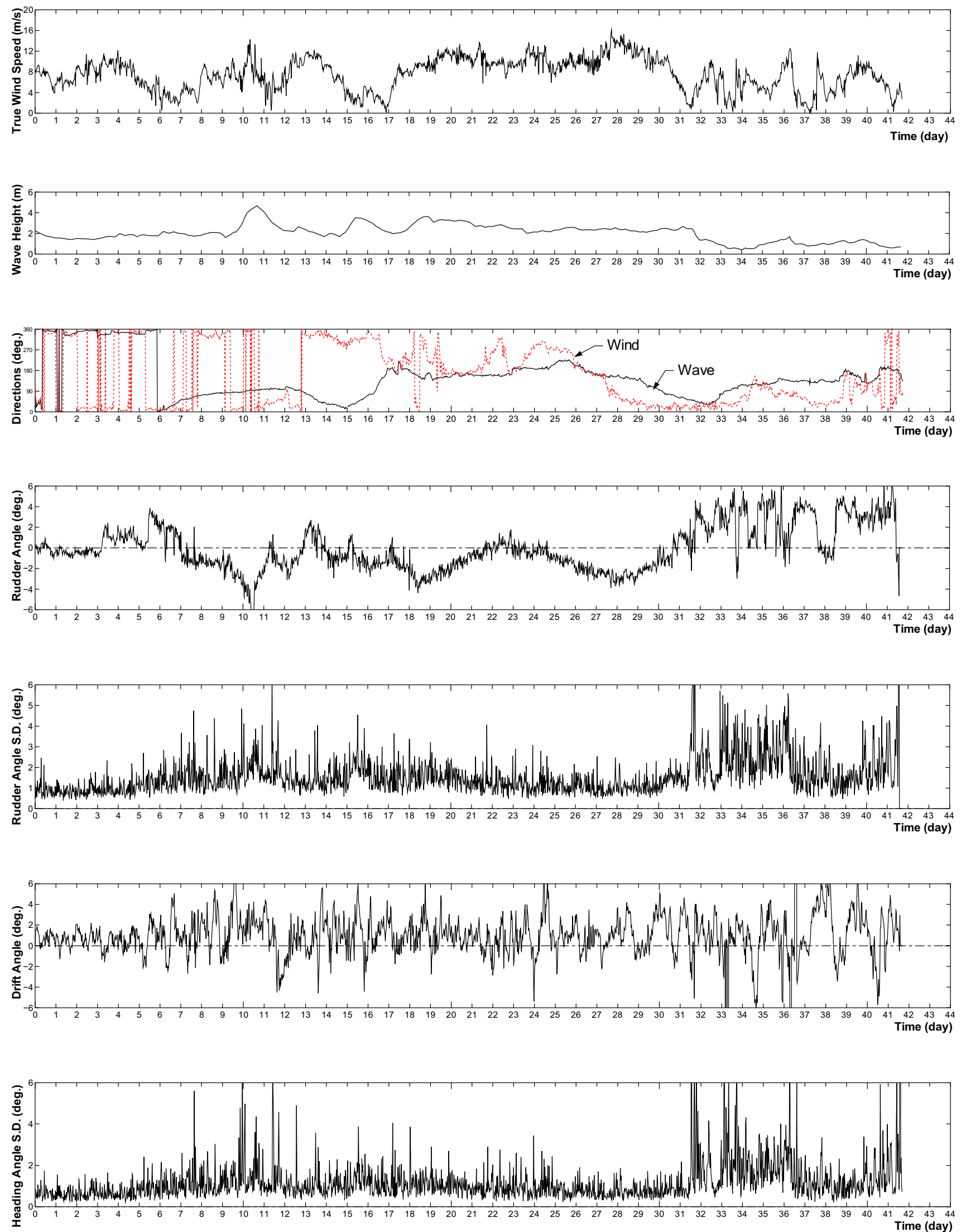

Fig. 5 Monitored weather and performance data, voyage case 1 

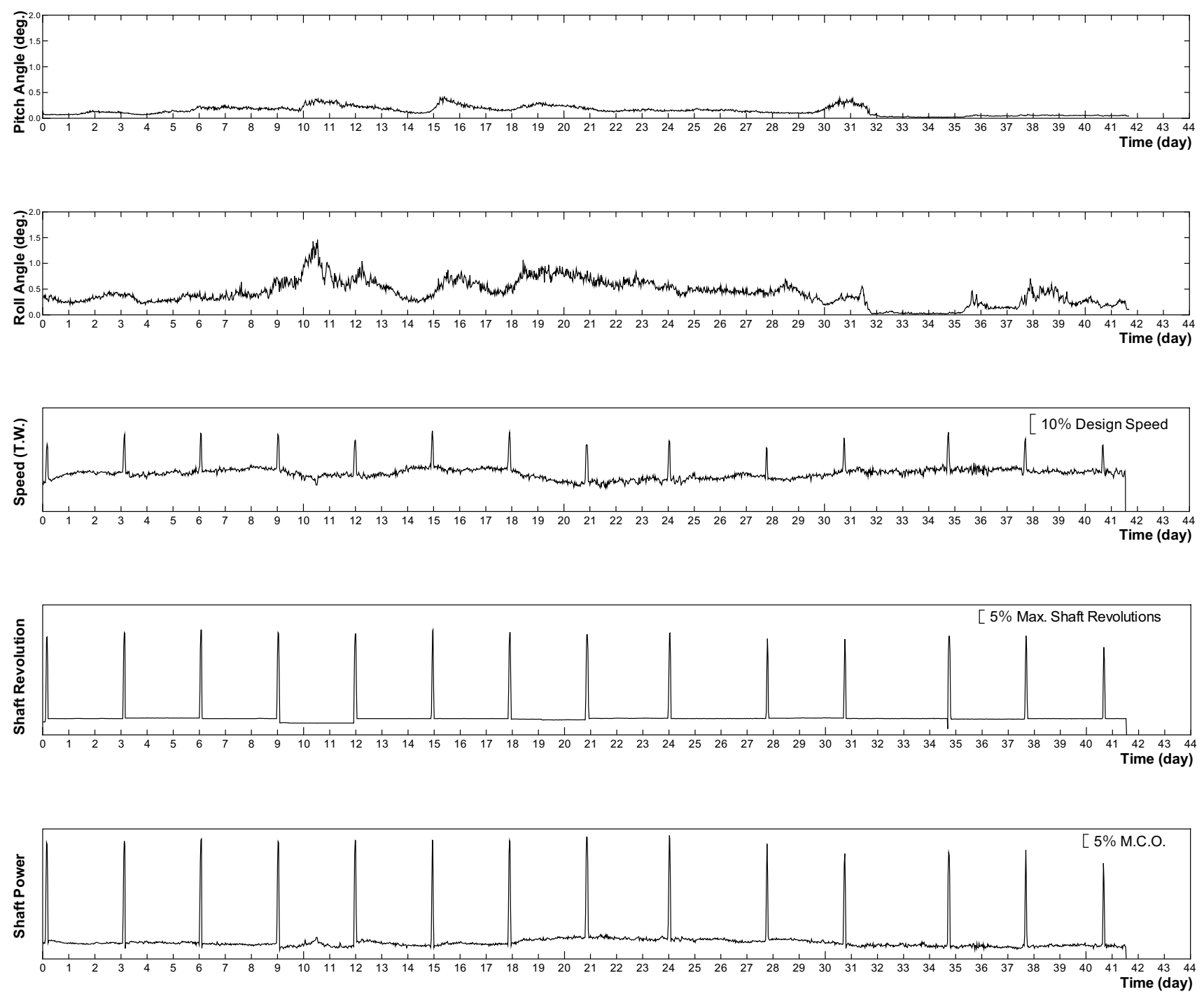

Fig. 5 (continued)

the 20 min average data are shown for each measured item. The spike-like behaviors shown in the figures of shaft revolutions and power are due to short-time speed ups for cleaning of the main engine turbocharger or soot-blowing procedures conducted at an interval of about 3 days during slow-steaming operations. Since wave measurement was not conducted on the ship, the forecast wave data were used in place of measured data. In total, about 2000 data samples (each processed from 20 min of raw time series data) were obtained.

\subsubsection{Evaluation of full-scale performance in still-water condition}

This case of performance evaluation is intended to evaluate the ship's performance in the still-water condition (no wind and no wave condition). With most dry cargo vessels, this type of performance in the design loaded condition cannot be verified in the new-building speed trials mentioned in the Introduction. Therefore, evaluation from monitoring data is of significant practical importance from the viewpoint of ship design.

First, monitored data are scrutinized so that the amount of correction applied to the data and the scattering of the corrected data reduced to certain level. The setting of the threshold vales is determined through the parameter study of each component of disturbances on the data correction. Figure 7 shows the example of filtering parameter study results for the case of a particular voyage data of the subject ship. In this examination, the variations of the corrected shaft power are examined by changing a particular parameter (true wind speed and significant wave height) with the reaming parameters fixed. This figure shows that 

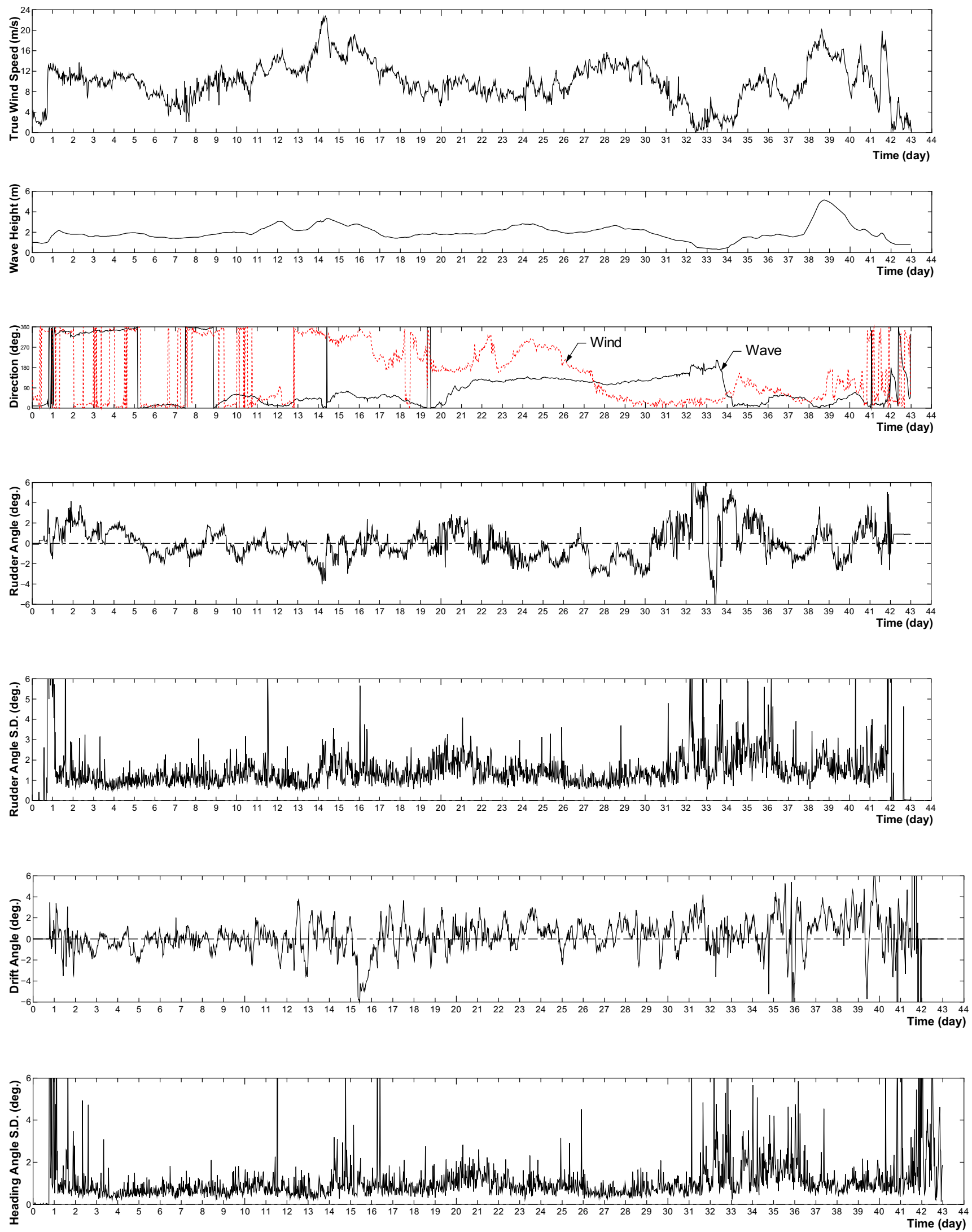

Fig. 6 Monitored weather and performance data, voyage case 2 

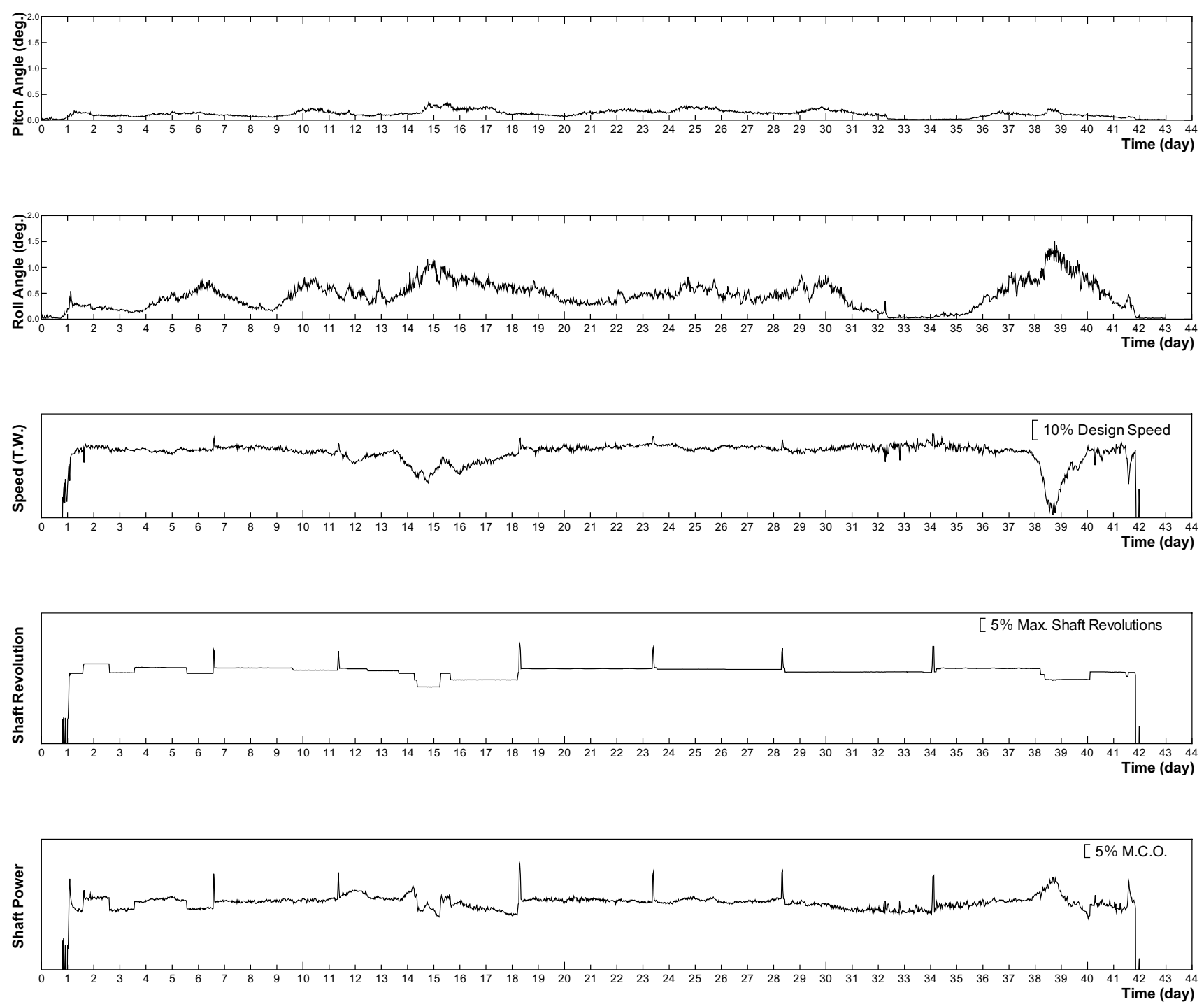

Fig. 6 (continued)

the corrected values are converged within certain level by decreasing the threshold of filtering.

From the accuracy point of view, stringent threshold setting is desirable, but this makes it difficult to obtain enough samples for the analysis. Thus, the following criteria for data scrutiny are determined as a compromise between the smallness of data correction and scattering and the scrutinized data size and applied to the still-water performance evaluation:

1. Average true wind speed for $20 \mathrm{~min}$ is less than $4.0 \mathrm{~m} / \mathrm{s}$.

2. Significant wave height is less than $2.0 \mathrm{~m}$.

3. Average rudder angle and standard deviation (SD) for $20 \mathrm{~min}$ are less than $2.0^{\circ}$.
4. Maximum difference of rudder angle for $20 \mathrm{~min}$ is less than $5.0^{\circ}$.

5. Average shaft revolution for $20 \mathrm{~min}$ is greater than $70 \%$ of maximum revolution.

6. Difference between consecutive average shaft revolutions for each 20 min period is less than $5 \%$ of the maximum revolution.

7. Pitch angle standard deviation (SD) for $20 \mathrm{~min}$ is less than $0.25^{\circ}$.

8. Roll angle standard deviation (SD) for $20 \mathrm{~min}$ is less than $0.50^{\circ}$.

The above data scrutiny is principally intended to select data monitored under small disturbances due to both encountered weather (wind and waves) and intentional steering and propelling machinery operation. Setting 

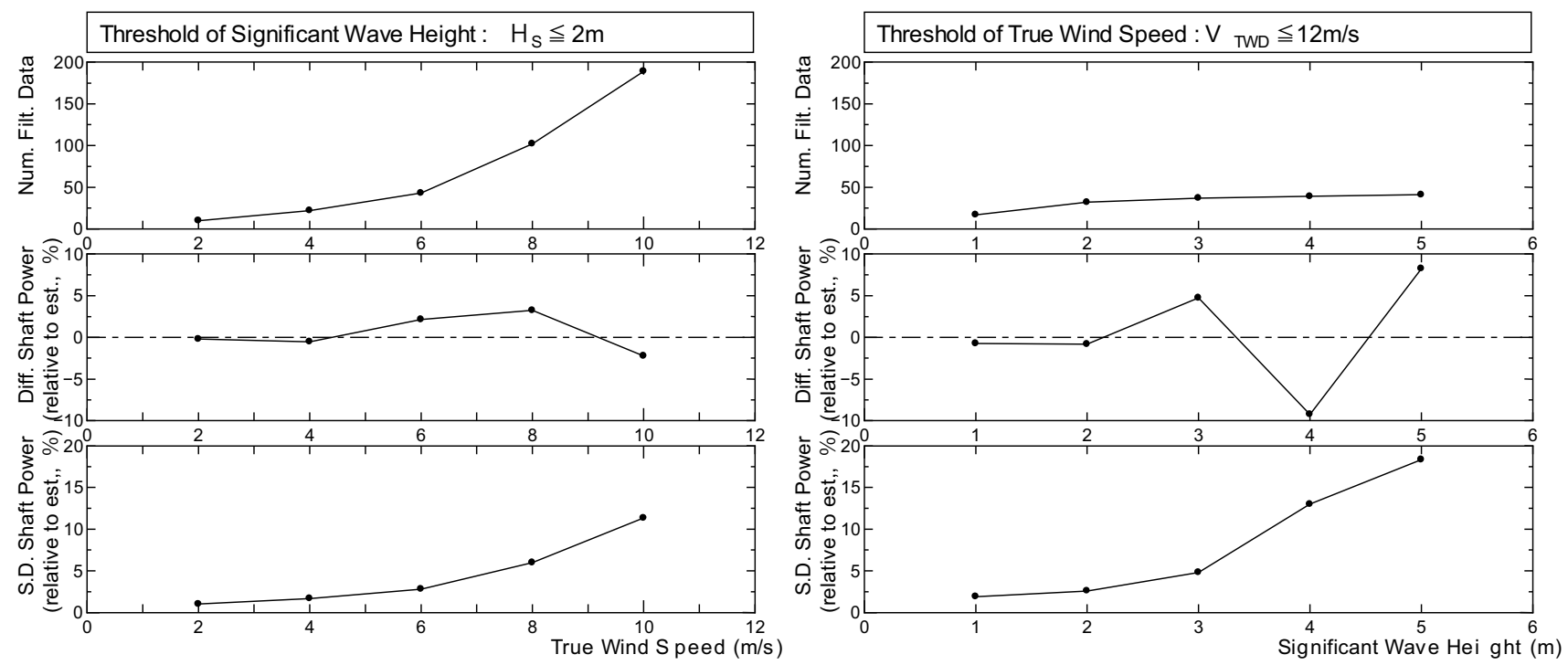

Fig. 7 Effects of threshold setting for filtering on the performance correction

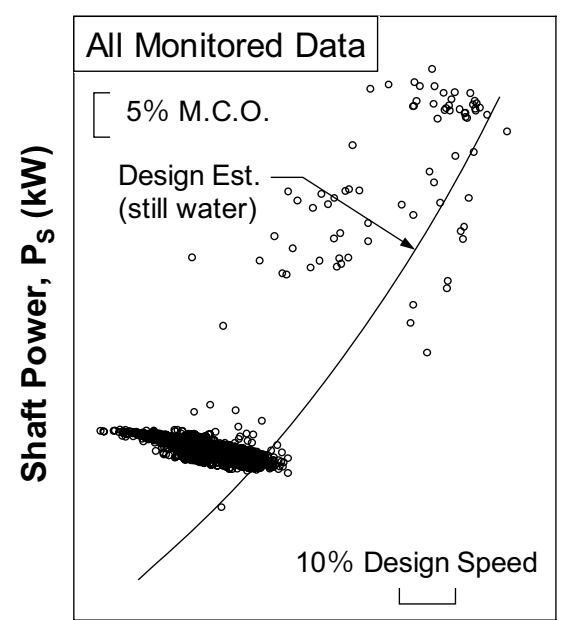

Speed (T.W.)

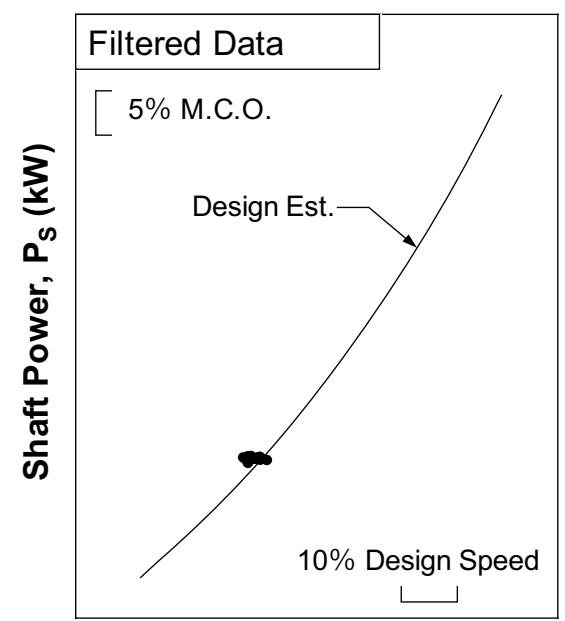

Speed (T.W.)

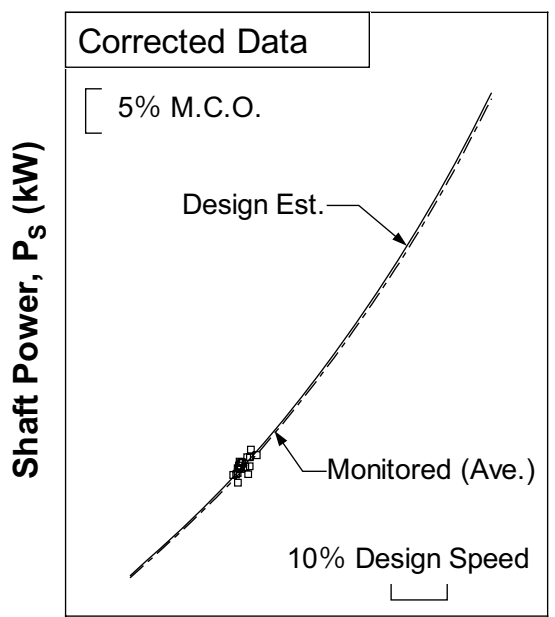

Speed (T.W.)

Fig. 8 Comparison of speed-power performance, voyage case 1

stringent criteria for data scrutiny makes it possible to obtain high-quality data which requires only small corrections for the disturbances.

After data scrutiny, about 30 samples were obtained. All the selected data are shown in the form of speed-power relationships in Figs. 8 and 9, together with the estimated speed-power curve predicted in the design stage by the JTTC method [19] from the model test results of resistance, selfpropulsion factors and propeller open water characteristics.

The JTTC method [19] is a kind of RTIM and one of the widely used methods for the still-water speed-power performance prediction which estimates the full-scale still-water performance from model test results. This method is based on the following assumptions:
1. The influence of propeller loading on self-propulsion factors except for wake fraction can be neglected.

2. Propeller open-water characteristics can be evaluated in a zone of Reynolds number during model test where the scale effect of the open-water characteristics decreases to be a negligibly small.

Thus the scale effect is considered in both total resistance $\left(R_{\mathrm{T}}\right)$ and wake fraction factor $(1-w)$. Full-scale total resistance is estimated from model resistance test results by means of a form factor method in which both form factor $(1+k)$ and resistance coefficient $C_{\mathrm{w}}$ are assumed to be the same for model and ship. Self-propulsion factors are evaluated in model self-propulsion tests by means of the thrust 


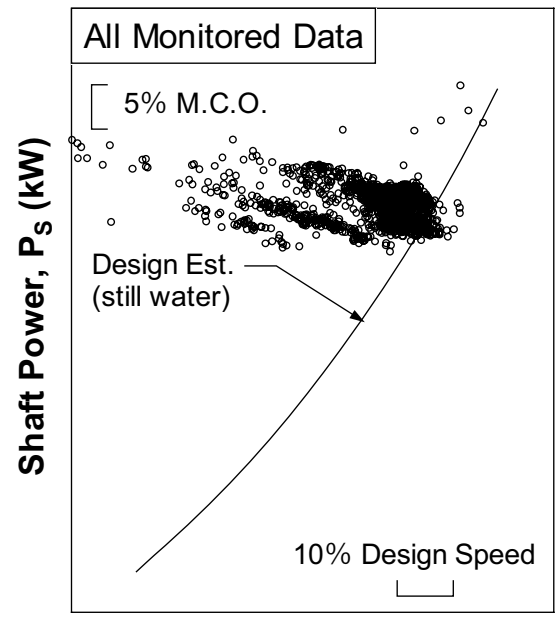

Speed (T.W.)
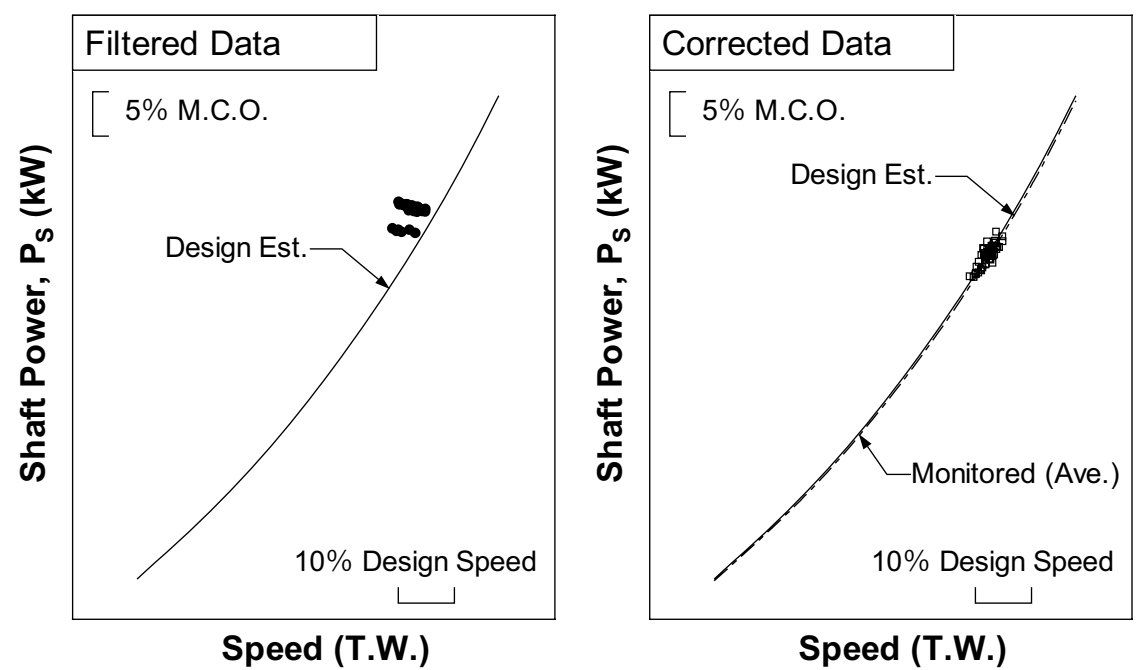

Fig. 9 Comparison of speed-power performance, voyage case 2

identity approach in which the propeller produces the same thrust in a wake field of wake fraction $w$ as in open-water with speed of $(1-w) \cdot V_{\mathrm{S}}$ for the same rpm, fluid properties, etc. [16]. Then the load factor of the propeller is determined by Eq. (18) using $R_{\mathrm{T}, \mathrm{S}}$ (estimated still-water resistance) in place of $R_{\mathrm{T}, \mathrm{S}, \mathrm{Crct}}$ (analyzed still-water resistance with corrections for disturbances). The propeller advance coefficient at self-propulsion point in still water is determined by Eq. (19) with the estimated propeller load factor. Propeller openwater efficiency is determined by using Eqs. (6), (7) and (20) with the estimated advance coefficient. Finally, speed-power relationship in still water is determined using the estimated total resistance, self-propulsion factors and propeller openwater efficiency.

In Figs. 8 and 9, three types of comparison are shown for (1) all the monitored data, (2) filtered data according to the above-mentioned criteria (1) through (8), and (3) corrected data reduced to the still-water equivalent condition by eliminating the effects of disturbances according to the procedures described in Sect. 3. The right-hand figures in Figs. 8 and 9 show the corrected speed-power data with the estimated curve. These figures include the corrected speed-power curve calculated by using the revised modelship correlation allowances obtained from the full-scale analysis results.

As can be clearly seen in Figs. 8 and 9, the corrected speed-power data and its curve show a quite good correlation with the design estimated curves calculated by the stillwater performance prediction method based on the "thrust identity" approach from towing tank model test data. In addition, the scatter of the corrected data around the mean corrected curve is relatively small, being equivalent to a standard deviation of about $1 \%$ of the ship's design speed.
These favorable corrected results for Ship A imply not only the correctness of the design performance but also the adequacy of the present procedure of performance monitoring and analysis as a means of full-scale evaluation.

\subsubsection{Evaluation of full-scale performance in actual seas}

The evaluation of performance in actual seas was carried out for the test ship by using the data from laden voyage cases of about 40 days each. The voyage cases are the same as those selected for the still-water performance analysis.

Figure 10 shows an example of the monitored data in actual seas divided into groups of wind directions, where $\theta$ denotes the true wind direction relative to the ship's heading. The three groups of $\theta$ correspond to the cases of head wind $\left(0^{\circ} \leqq \theta<15^{\circ}\right.$, about 350 samples), beam wind $\left(75^{\circ} \leqq \theta<105^{\circ}\right.$, about 250 samples) and following wind $\left(165^{\circ} \leqq \theta \leqq 180^{\circ}\right.$, about 150 samples), respectively. The effect of the true wind direction $(\theta)$ on speed-power performance can be seen in the figure. That is, horizontal spread of data samples, which corresponds to the speed reduction due to encountered disturbances, decreases with increasing true wind direction, in particular from the head wind case to the beam and following wind cases. While the difference between the beam and following wind cases is small, this is mainly due to the fact that effects of wind waves (added resistance in wind waves) under these wind conditions are small and of similar magnitude for both these wind cases.

As in the still-water performance analysis, data scrutiny is conducted according to the following criteria to select appropriate data for the performance evaluation. In this case, the data scrutiny is conducted mainly to eliminate the data both under excessive steering and maneuvering 

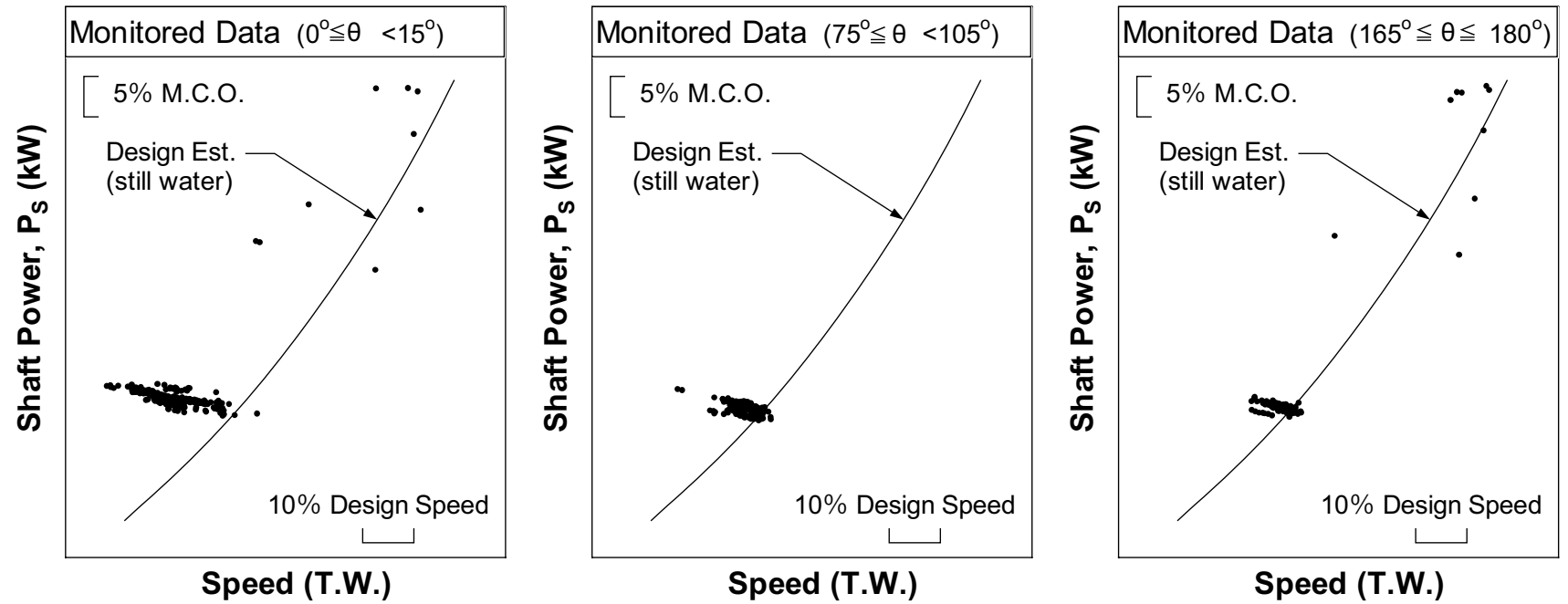

Fig. 10 Comparison of speed-power performance for different ranges of wind direction
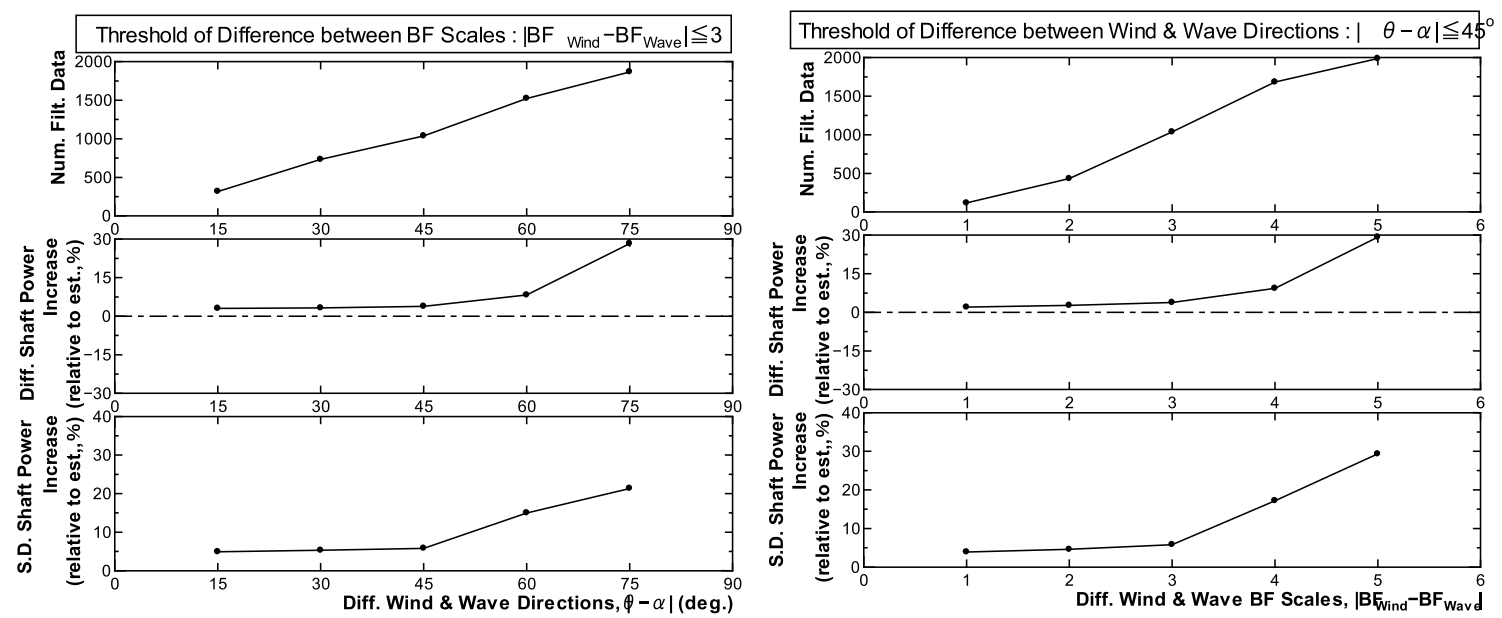

Fig. 11 Effects of threshold setting for filtering on the performance correction

motion and in wave environments different from the Beaufort standard condition. The setting of the threshold vales is determined through the parameter study of each component of disturbances on the data correction. Figure 11 shows the example of filtering parameter study results for the case of a particular voyage data of the subject ship. In this examination, the variations of the corrected shaft power are examined by changing a particular parameter (1) difference between average true wind angle $(\theta)$ and mean wave direction $(\alpha)$ and (2) difference between encountered true wind speed-based $\mathrm{BF}$ scale $\left(\mathrm{BF}_{\text {wind }}\right)$ and encountered wave-height based $\mathrm{BF}$ scale $\left(\mathrm{BF}_{\text {wave }}\right)$ with the reaming parameters fixed. This figure shows that the corrected values are converged within certain level by decreasing the threshold of filtering.
1. Difference between average true wind angle $(\theta)$ and mean wave direction $(\alpha)$ is less than $45^{\circ}$.

2. Difference between encountered true wind speed-based $\mathrm{BF}$ scale $\left(\mathrm{BF}_{\text {wind }}\right)$ and encountered wave-height based $\mathrm{BF}$ scale $\left(\mathrm{BF}_{\text {wave }}\right)$ is less than 3 (see Fig. 3).

3. Standard deviation (SD) of true wind direction for $20 \mathrm{~min}$ is less than $15.0^{\circ}$.

4. Rudder angle standard deviation (SD) for $20 \mathrm{~min}$ is less than $3.0^{\circ}$.

5. Maximum difference in rudder angle for $20 \mathrm{~min}$ is less than $6.0^{\circ}$.

6. Standard deviation (SD) of ship's heading for $20 \mathrm{~min}$ is less than $3.0^{\circ}$.

7. Average shaft revolution is greater than $70 \%$ of the maximum shaft revolution. 
8. Difference between consecutive average shaft revolutions for each 20 min period is less than $5 \%$ of the maximum shaft revolution.

Fig. 12 Comparison of shaft power increase, voyage case 1
In this case of analysis, the ship's performance is corrected for the difference of weather disturbances due to wind and waves. That is, the resistance increase due to wind is corrected by taking into account the difference between the encountered true wind direction and the
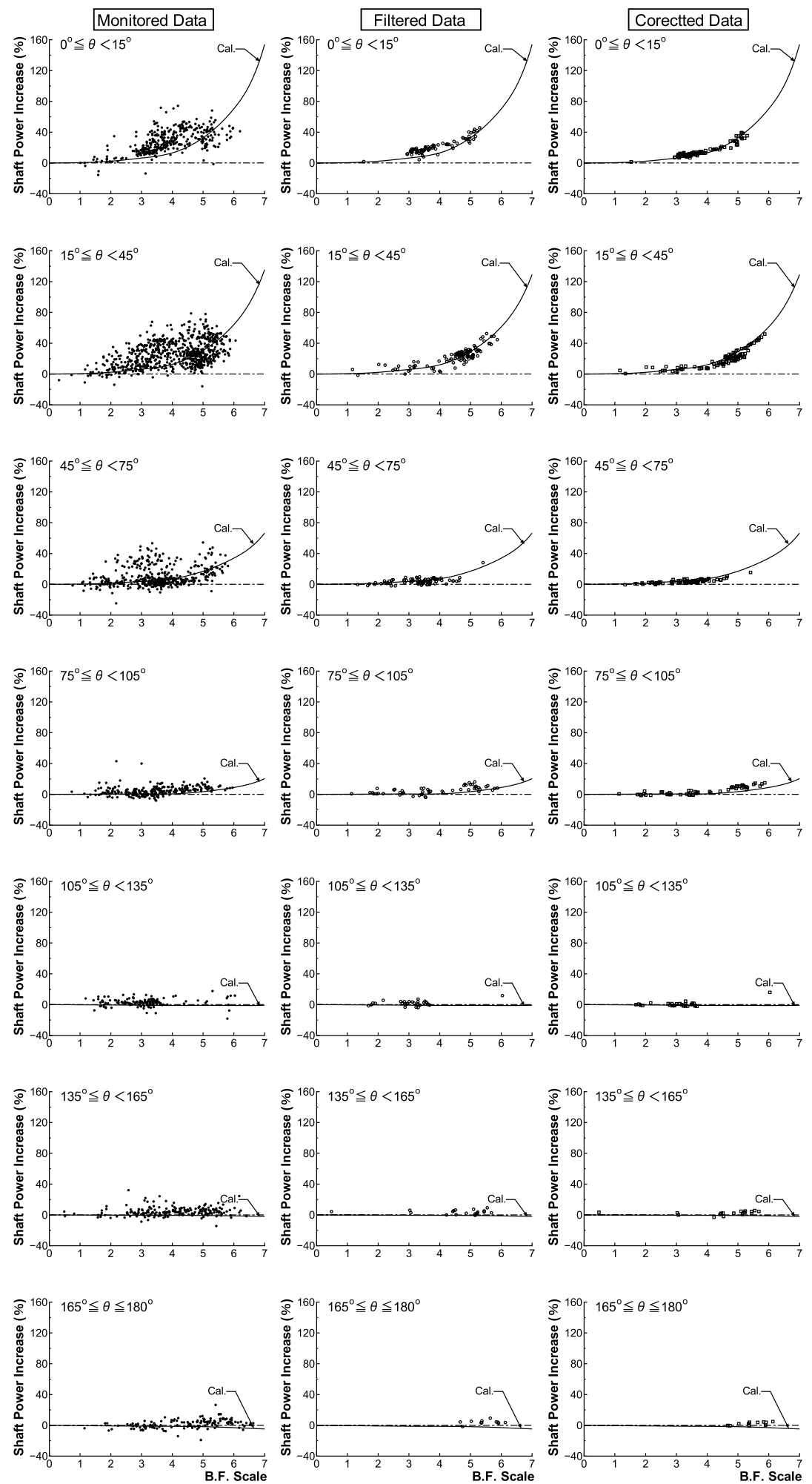
Fig. 13 Comparison of shaft power increase, voyage case 2
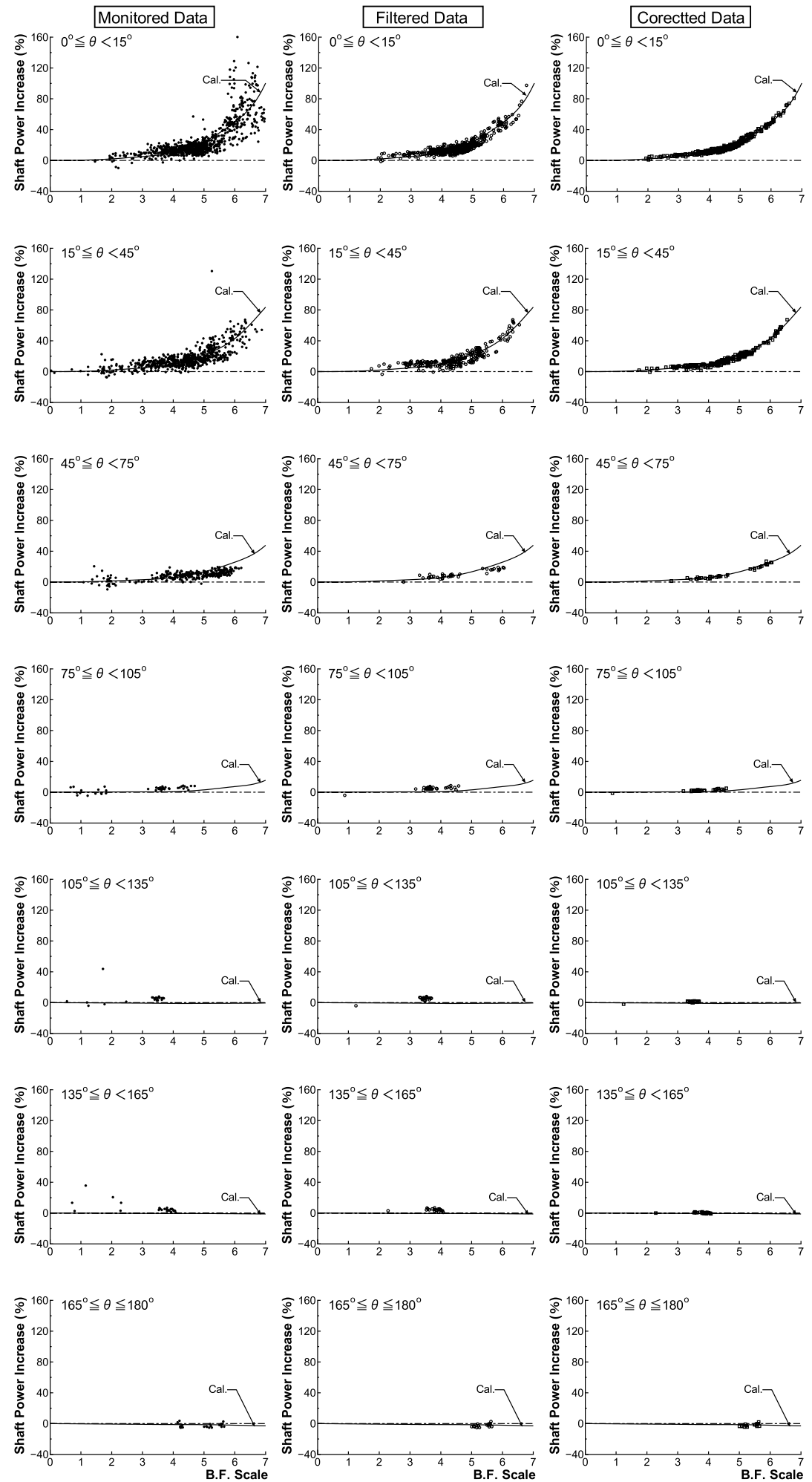

reference true wind direction defined in Eq. (28), and the resistance increase due to waves is adjusted by substituting the estimated resistance increase under the actual wave condition with that corresponding to the Beaufort standard condition based on the encountered true wind speed by Eq. (29).

The corrected performance under the Beaufort standard weather condition is evaluated in terms of the shaft power increase, which denotes the percent increase of power 
relative to the power in still water at the same ship's speed through water. A comparison of the corrected performance and the estimated shaft power increase curve is shown in Figs. 12 and 13 for a group of wind/wave directions.

Power increase is estimated as a difference between the speed-power curves in both still water and the Beaufort standard weather condition. Speed-power relationship in the Beaufort condition is made by the same procedure as the JTTC method for still-water case described in Sect. 4.2.2. By replacing total resistance in still water with that in the Beaufort condition which includes the effects of wind and waves, Speed-power curve in the Beaufort condition is obtained in a straightforward manner. It is noted that the estimation is made under the assumption that the influence of propeller loading on self-propulsion factors except for wake fraction can be neglected.

In these figures, the shaft power increase is presented against the true-wind speed based BF scale. Three types of data consisting of raw monitored data $(\bullet)$, filtered data (O) and corrected data $(\square)$ are shown in the graphs at the left, center and right, respectively. The data size are reduced to about $50 \%$ of the original data by applying scrutiny criteria (1) through (8). The differences between filtered $(O)$ and corrected $(\square)$ represent the effect of the difference in wave conditions between the actual weather and the Beaufort standard weather, which assumes fully developed wind waves. The physical meanings of the corrections applied in this analysis are the effects of swell and the differences of the mean periods and encounter directions of waves. In the case where the swell effect is predominant, the corrected sea margin is noticeably reduced from the monitored data. On the other hand, in the case where the encounter directions of wind and waves differ by large amounts, the correction can be noticeable because the resistance increase due to waves changes significantly with the encounter angle. If the wave encounter direction is smaller (that is, closer to the bow) than the encounter wave direction, the wave resistance increase is corrected to a smaller amount than that corresponding to the actual encountered wave condition.

As is clearly shown in Figs. 12 and 13, the corrected shaft power increases correlate quite well with the estimated curves. It is also noted that the corrections of the shaft power increase data due to the difference in wave conditions are relatively small, that is, the order of correction is less than $10 \%$ for most of the filtered data.

To evaluate the nature of these characteristics in more detail, the averaged difference of the shaft power increase (SPI) in the monitored data and calculated data was evaluated, as shown in Fig. 14. In this figure, the root mean squares of the difference in the shaft power increase (RMS (Diff. SPI)) calculated by Eq. (31) are shown on the base of the encountered wind and wave direction $(\theta)$.

$\operatorname{RMS}($ Diff. SPI $)=\sqrt{\frac{1}{N} \sum_{i=1}^{N}\left(\mathrm{SPI}_{\text {moni }}-\mathrm{SPI}_{\text {cal }}\right)^{2}}$,

where $N$ is the number of monitored data, and $\mathrm{SPI}_{\text {moni }}$ and SPI $_{\text {cal }}$ are the monitored and calculated SPI values, respectively.

Although the differences in all data cases are noticeable compared to those in the still-water condition, these differences are reduced by applying filtering and corrections. The difference between the filtered and corrected results is less than $2 \%$, and the corrected data are generally smaller than $3 \%$.
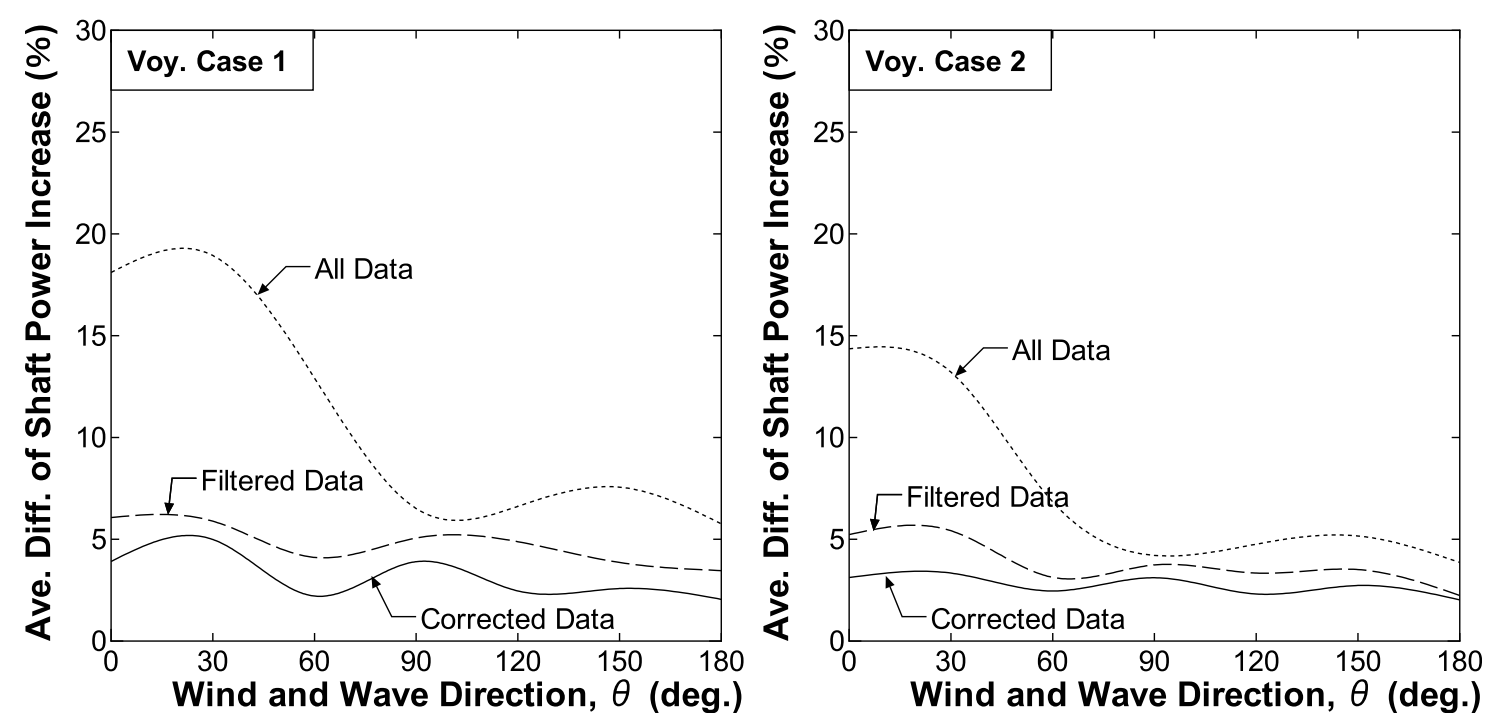

Fig. 14 Comparison of speed-power performance 
These results clearly imply that there exists a noticeable difference in wave conditions between actual weather and the wind speed-based Beaufort standard wave condition and that ship's performance evaluations in actual seas should be conducted by imposing stringent scrutiny criteria considering the actual wave conditions and selecting the data under conditions similar to those assumed in the performance predictions, instead of evaluating monitored data solely on the basis of the wind speed-based Beaufort scale, as is done in normal service performance analyses.

The agreement between the corrected results and the predictions of the shaft power increases in actual seas under a wide range of wind and wave conditions presented here clearly shows that a ship's performance in service can be estimated by using the present prediction method as far as the weather conditions are similar to the Beaufort standard weather conditions defined in this study. It should also be stressed that speed-power performance is affected significantly by encountered waves, and an accurate evaluation of their effect is indispensable for enhancing the accuracy of full-scale performance monitoring and analysis under varied weather conditions dissimilar from the Beaufort standard weather condition, such as wave environments with dominant swell effects.

\section{Conclusions}

In this paper, the full-scale ship performance in actual seas predicted by the method described in part 1 of the present study has been validated by a comparison with onboard monitored data.

The full-scale performance of a large bulk carrier was monitored by means of a dedicated on-board monitoring system. The monitored data were thoroughly analyzed and reduced to the form of performance parameters applicable to the comparison with the prediction results.

The full-scale ship's performance predictions in still water and in wind and waves agree quite well with the analyzed data of the monitored service performance. The agreement between the corrected results and the predictions clearly implies that a ship's performance in service can be estimated by using the present prediction method as far as the weather conditions are similar to those assumed in the predictions.

It should also be stressed that speed-power performance is affected significantly by encountered waves, and an accurate evaluation of their effect is indispensable for enhancing the accuracy of full-scale performance monitoring and analysis under varied weather conditions dissimilar from the Beaufort standard weather, such as wave environments with dominant swell effects.
Open Access This article is distributed under the terms of the Creative Commons Attribution 4.0 International License (http://creativecommons.org/licenses/by/4.0/), which permits unrestricted use, distribution, and reproduction in any medium, provided you give appropriate credit to the original author(s) and the source, provide a link to the Creative Commons license, and indicate if changes were made.

\section{References}

1. Orihara H, Yoshida H (2010) Development of voyage support system "Sea-Navi" for lower fuel consumption and $\mathrm{CO}_{2}$ emissions. In: Proceedings of the international symposium on ship design and operation for environmental sustainability, London, pp 315-328

2. Orihara H, Yoshida H, Amaya I (2016) Evaluation of full-scale performance of large merchant ships by means of on-board performance monitoring. In: Proceedings of the 26th international ocean and polar engineering conference, Rhodes

3. Telfer EV (1926) The practical analysis of merchant ship trials and service performance. Trans North East Coast Inst Eng Shipbuild 43 Part 2:123-177

4. Clements RE (1957) A method of analyzing voyage data. Trans North East Coast Inst Eng Shipbuild 73 Part 4:197-230

5. Logan A (1960) Service performance of a fleet of tankers. Trans North East Coast Inst Eng Shipbuild 76 Part 7:s61-s78

6. Mizokami $\mathrm{S}$ et al (2006) Monitoring of service performance of a ROPAX Ferry. Conf Proc Jpn Soc Nav Archit Ocean Eng 3:437440 (in Japanese)

7. Ebira K et al (2007) Propulsive performance of a $145,000 \mathrm{~m}^{3} \mathrm{LNG}$ carrier by voyage data record and analysis system. Conf Proc Jpn Soc Nav Archit Ocean Eng 4:313-316 (Japanese)

8. Furustam J (2016) On ways to collect and utilize data from ship operation in naval architecture. In: Proceedings of the 15th international conference on computer and IT applications in the maritime industries (COMPIT'16), Lecce, pp 430-438

9. Gundemann D, Dirksen T (2016) A statistical study of propulsion performance of ships and the effects of dry dockings, hull cleanings and propeller polishes on performance. In: Proceedings of the 1st hull performance and insight conference (HullPIC'16), Castello di Pavone, Italy, pp 282-291

10. Gunnsteinsson S, Clausen JW (2016) Enhancing performance through continuous monitoring. In: Proceedings of the 15 th international conference on computer and IT applications in the maritime industries (COMPIT'16), Lecce, pp 471-480

11. Solonen A (2016) Experiences with ISO-19030 and beyond. In: Proceedings 1st hull performance and insight conference (HullPIC'16), Castello di Pavone, Italy, pp 152-162

12. Ando $H$ (2011) Performance monitoring for energy efficient fleet operation. J Soc Instrum Control Eng 50(6):1-7

13. Saito $\mathrm{Y}$ et al (2012) On-board monitoring system integrated in optimum navigation control system. Conf Proc Jpn Soc Nav Archt And Ocean Engineers, vol 15, pp 35-38 (in Japanese)

14. Kimura $\mathrm{K}$ et al (2012) Ship performance estimation and operation support using fleet monitoring. Conf Proc Japan Soc Naval Archit Ocean Eng 15:39-41 (Japanese)

15. ISO15016.2015 (2015) Ships and marine technology—guideline for the assessment of speed and power performance by analysis of speed trial data

16. Bertram V (2000) Practical ship hydrodynamics. ButterworthHeinemann, Oxford

17. ITTC/RP.7.5.-02-07-02.2 (2011) ITTC-recommended procedures, prediction of power increase in irregular waves from model test

18. WNO (1995) Manual of codes, international codes, vol I.1, Part A-Alphanumeric codes, WNO-No.306 (1995 edition) 
19. Tamura K (1975) Speed and power prediction techniques for high block ships applied in Nagasaki experimental tank. In:
Proceedings of the first ship technology and research symposium, Washington, DC, pp 7-1-7-17 